\title{
Evolução Composicional dos Filossilicatos no Perfil Intempérico do Complexo Ultramáfico Alcalino-carbonatítico de Catalão I (GO)
}

\section{The Compositional Evolution of the Phyllosilicates in the Lateritic Profile of the Catalão I Ultramafic Alkaline-carbonatitic Complex (GO)}

\author{
Rogério Guitarrari Azzone (rgazzone@usp.br)e Excelso Ruberti (exrubert@usp.br) \\ Departamento de Mineralogia e Geotectônica - Instituto de Geociências - USP \\ R. do Lago 562, CEP 05508-080, São Paulo, SP, BR
}

Recebido em 06 de outubro de 2009; aceito em 09 de fevereiro de 2010

\section{RESUMO}

A evolução composicional dos filossilicatos no perfil laterítico do complexo ultramáfico alcalino-carbonatítico de Catalão I (GO) é proposta neste trabalho por meio de estudos petrográficos, de difratometria de raios X e química mineral (WDS) por microssonda eletrônica. Os minerais micáceos encontrados no nível rocha sã são classificados como flogopita (associada a diferentes paragêneses) e tetraferriflogopita (produto de metassomatismo). Nos níveis Rocha Alterada e Saprólito Isoalterítico, os filossilicatos derivados de micas são vermiculita e interestratificado regular flogopita-vermiculita (formação e características similares aos da hidrobiotita), caracterizando um processo principal de vermiculitização neste perfil. Subordinadamente, em porções superiores e pontuais do nível isoalterítico, a alteração da flogopita vermiculitizada gera produtos esmectíticos, caracterizados principalmente pela ocorrência de interestratificado regular expansível e mesmo pela ocorrência de esmectita. No topo do nível saprolítico e no nível aloterítico, há ocorrência de caolinita. A sequência evolutiva dos filossilicatos neste complexo apresenta a seguinte ordem de formação: flogopita, interestratificado flogopita-vermiculita, vermiculita, produtos esmectitizados (interestratificados expansíveis de ocorrência pontual), esmectita e caolinita, sendo os dois últimos provavelmente associados à contribuição supérgena. Tal sequência é compatível com a das proposições mais recentes para a formação de argilominerais em solos. As principais diferenças entre as flogopitas e seus produtos da alteração vermiculítica dizem respeito aos teores de $\mathrm{K}^{+}$que diminuem significativamente, e à oxidação do $\mathrm{Fe}^{2+}$, mudanças estas próprias do processo de vermiculitização. No caso específico das vermiculitas, a posição interfoliar é preenchida predominantemente por $\mathrm{Mg}^{2+}$. Além disso, a presença de minerais interestratificados (produtos intermediários de alteração) é indicativa principalmente de perfis pouco alterados e relativamente recentes.

Palavras-chave: Vermiculita; Interestratificado flogopita-vermiculita; Perfil intempérico laterítico; Catalão I; Província Alto Paranaíba.

\begin{abstract}
The compositional evolution of the phyllosilicates in the lateritic profile of the Catalão I ultramafic alkaline-carbonatitic complex (GO) is proposed in this work based on petrographic and X-ray diffraction analysis, as well as, chemical composition obtained by WDS electron microprobe. The micaceous minerals found in unweathered rocks are classified as phlogopites (with different parageneses) and tetraferriphlogopites (metasomatic products). In the levels of altered rocks and isalteritic saprolite, the phyllosilicates derived from micas are vermiculite and regular interstratified phlogopite-vermiculite (which formation and characteristics are similar to hydrobiotite), characterizing a main vermiculitization process in this profile. Subordinately, in the upper portions and punctual areas of isalteritic saprolite, the alteration of the vermiculitized phlogopite generates smectitic products, which are characterized mainly by the occurrence of expansible regular interstratified mineral and even smectite. Kaolinite occurs on the top of the isalteritic saprolite and on the alloteritic level. The evolution sequence of the phyllosilicates in the weathering profile of the Catalão I complex presents the following formation order: phlogopite, interstratified phlogopite-vermiculite, vermiculite, smectitic products (expansible interstratified minerals of local occurrence),
\end{abstract}


smectite and kaolinite, of which, the last two are probably associated to supergene processes. This sequence is compatible with the most recent theories for the formation of clay minerals in soils. The main differences between the phlogopites and their products of vermiculitic alteration are related to a significant decrease of $\mathrm{K}^{+}$and oxidation of $\mathrm{Fe}^{2+}$, characteristic changes of the vermiculitization process. In the specific case of vermiculites, the interlayer site is filled mainly by $\mathrm{Mg}^{2+}$. In addition to that, the presence of interstratified minerals (intermediate alteration products) is a key indicator of relatively recent and low-altered weathering profiles.

Keywords: Vermiculite; Interstratified phlogopite-vermiculite; Lateritic weathering profile; Catalão I; Alto Paranaíba Province.

\section{INTRODUÇÃO}

As rochas carbonatíticas constituem fonte de bens minerais dos mais importantes, como grandes depósitos de fosfatos, nióbio e titânio. No Brasil, essas associações são responsáveis por cerca de $95 \%$ da capacidade nominal da produção nacional de concentrados fosfáticos (Lapido-Loureiro, Melo Monte, Nascimento, 2009). Nessas jazidas de fosfatos, ocorrem associados vários minerais de ganga, sendo mais frequentes os óxidos e hidróxidos de $\mathrm{Fe}$ (magnetita e goethita), micas (flogopita e biotita), vermiculita, minerais de titânio (ilmenita, perovskita e anatásio) e outros minerais em menor proporção (Guimarães e Lenharo, 2002). Na maioria dos depósitos brasileiros, incluindo Catalão I, o minério é residual, enriquecido pela alteração laterítica.

Nesses casos, o processo de laterização age, por um lado, concentrando a apatita nos primeiros estágios de intemperismo e, por outro lado, promovendo modificações químicas e morfológicas em toda a paragênese mineral, sendo que essas geram dificuldades na recuperação industrial do minério (Toledo et al., 2004a). Nesse sentido, problemas associados à presença de filossilicatos no beneficiamento de fosfatos foram encontrados em algumas usinas, resultando em perdas da ordem de $20 \%$ na recuperação de $\mathrm{P}_{2} \mathrm{O}_{5}$. Em razão dos tipos de filossilicatos presentes em um determinado depósito, podem ocorrer vários problemas tais como contaminação dos concentrados de apatita ou, para o caso de micas mais alteradas, geração de lamas nas condições usuais de atrição da célula mecânica de flotação, podendo tornar o processo menos seletivo.

O primeiro passo para a melhora desse processo está centrado em trabalhos de base visando ao conhecimento da paragênese desses minerais e sua evolução no perfil de alteração, proporcionando assim substrato significativo para posteriores trabalhos relacionados à extração e ao beneficiamento do minério. Dessa forma, este trabalho tem como objetivo o entendimento da evolução química e mineralógica dos filossilicatos nos diferentes horizontes intempéricos do complexo Catalão I.

\section{CONTEXTO GEOLÓGICO}

O complexo ultramáfico alcalino-carbonatítico de Catalão I ( $\left(18^{\circ} 08^{\prime} \mathrm{S}, 47^{\circ} 48^{\prime} \mathrm{W}\right)$ constitui uma estrutura dômica, com uma superfície de forma aproximadamente elíptica cujos eixos N-S e E-W medem 6 e 5,5 km, respectivamente, tendo seu relevo sustentado por um anel de rochas quartzíticas encaixantes fenitizadas (Carvalho, 1974).

Catalão I (85 Ma; Amaral et al., 1967; Sonoki e Garda, 1988) pertence à Província Ígnea Alcalina do Alto Paranaíba (Almeida, 1983; Ulbrich e Gomes, 1981). Representativa do magmatismo alcalino do Cretáceo Superior, esta província ocorre nas bordas da Bacia do Paraná, ao longo de falhas profundas de direção NW. É representada por um conjunto de rochas kamafugíticas, kimberlíticas e carbonatíticas sob a forma de diques, pipes, plugs, diatremas, exalações, lavas e grandes complexos plutônicos (Figura 1). A região corresponde a uma das volumetricamente mais extensas províncias máfico-potássicas no mundo (Gibson et al., 1995; Araújo et al., 2001; Gomes e CominChiaramonti, 2005).

Dentre os trabalhos que apresentam em detalhe feições geológicas, geoquímicas, petrológicas e mineralógicas do complexo podem citar-se Carvalho (1974), Hirano et al. (1987), Baecker (1983), Danni et al. (1991), Araújo e Gaspar (1992), Lapido-Loureiro (1995), Pereira (1995), Oliveira e Imbernon (1998), Toledo (1999, 2000), Brod et al. (2001), Toledo et al. (2004a, 2004b) e Gomes e CominChiaramonti (2005).

Em Catalão I flogopititos e carbonatitos são os tipos de rocha mais abundantes, ocorrendo em complexas associações em que se alterna a predominância de um tipo sobre o outro. Dunitos, piroxenitos, foscoritos e rochas vulcanoclásticas estão presentes subordinadamente. Em sua maioria, porém, as rochas de Catalão I encontram-se completamente intemperizadas, constituindo um manto laterítico que chega atingir mais de $100 \mathrm{~m}$ de profundidade (Figura 2a). Rochas frescas somente podem ser encontradas em profundidade por meio de furos de sondagem ou pontualmente nos níveis inferiores das frentes de lavra. Combinando os furos de sondagens e as associações encon- 


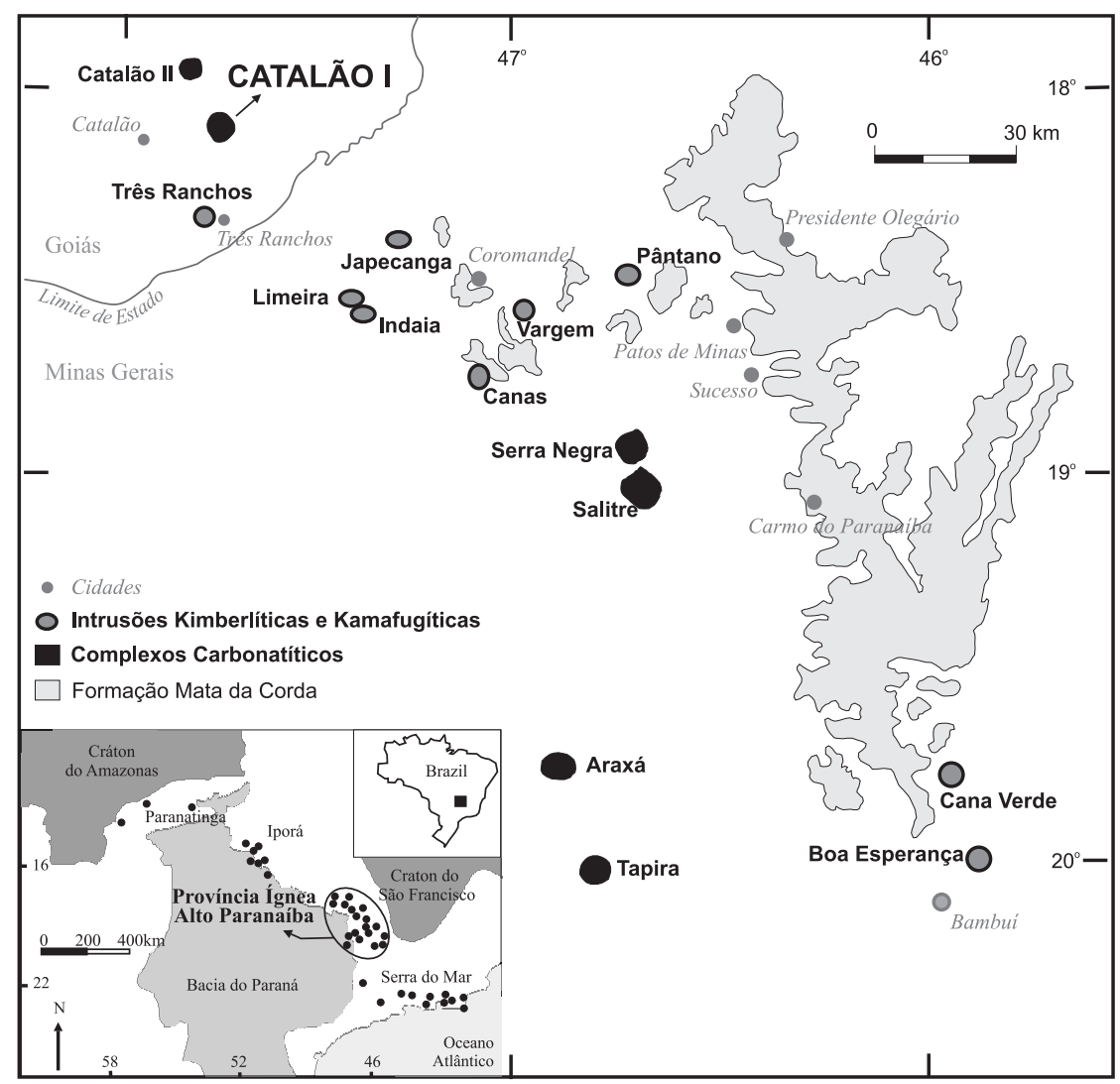

Figura 1. Mapa de localização das principais intrusões da Província Alcalina do Alto Paranaíba e da Formação Mata da Corda, segundo Meyer et al. (1994). No detalhe, a localização da Província Alto Paranaíba em relação aos principais domínios estruturais brasileiros (Gibson et al., 1995).

tradas nas frentes de lavra, Ribeiro (1998) apresenta um mapa geológico da área do complexo lavrada pela Ultrafértil S.A., e mostra a associação de flogopititos e carbonatitos e zonas de carbonatitos enriquecidos em $\mathrm{Nb}, \mathrm{Ba}, \mathrm{Mg}$ e terras-raras (Figura 2b).

O perfil de alteração laterítica de Catalão I é extremamente complexo, contendo abundante quantidade de apatita, pirocloro, monazita, minerais de Ti (perovskita, ilmenita e anatásio) e vermiculita. Oliveira e Imbernon (1998), com base em características petrológicas e químicas, definem tal manto intempérico em 4 horizontes distintos, a saber, Rocha Alterada, Saprólito Isoalterítico, Saprólito Aloterítico e Solo (material alóctone). Destes, apenas os níveis Rocha Alterada e Saprólito Isoalterítico são explorados como minério (principalmente de fosfatos). De modo geral, Imbernon (1993) mostra que as principais transformações ocorridas no processo de alteração podem ser divididas em três estágios. Num estágio inicial, há progressiva diminuição na quantidade de carbonatos, por dissolução, e concentração relativa de apatita e minerais acessórios. A flogopita também sofreu concentração residual, porém transformada em vermiculita, que é muito bem identificada macroscopicamente. $\mathrm{O}$ aparecimento de quartzo, neste início de alteração, pode ser creditado à neoformação supérgena, a partir da hidrólise dos silicatos (Imbernon, 1993). Num estágio intermediário, ocorre a completa dissolução dos carbonatos e quase total desaparecimento de vermiculita. A apatita apresenta concentração residual e fosfatos aluminosos secundários possuem concentração absoluta, assim como a presença de quartzo e barita neoformados a partir dos níveis superiores. No estágio final, há a neoformação de sesquióxidos de Fe, desaparecimento total de apatita e ocorrência de caolinita. A silicificação é menos intensa, provavelmente devido à dissolução de quartzo, que precipita em níveis inferiores do perfil. Ressalte-se, porém, que esses estágios se desenvolvem de maneira bastante heterogênea em todo o perfil, sendo identificados em diferentes escalas e orientações. Esse processo 


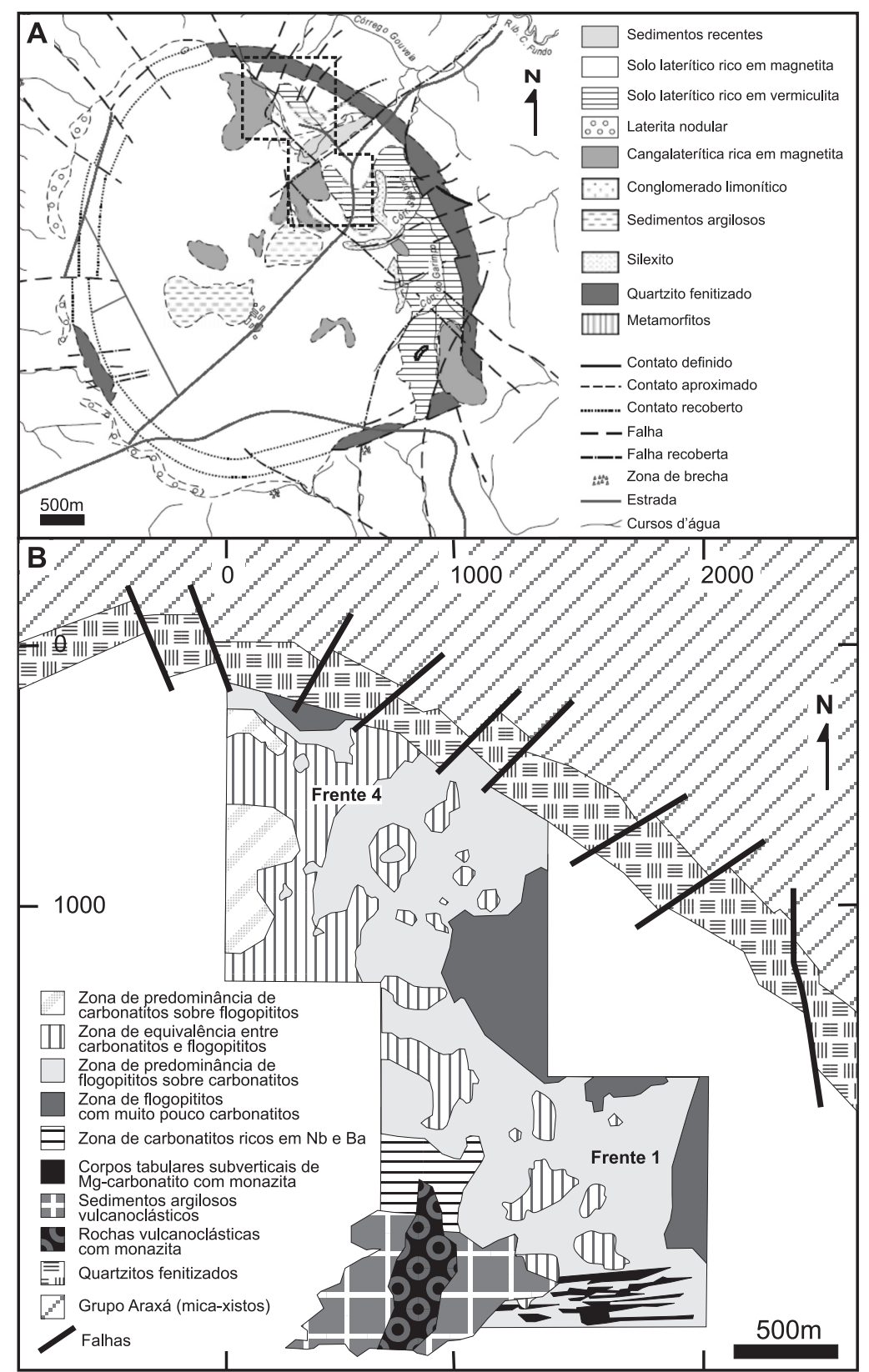

Figura 2. A. Mapa das formações superficiais do Complexo Catalão I (Carvalho, 1974; Baecker, 1983). B. Mapa geológico do Complexo Catalão I na área de lavra da Ultrafértil S.A. (Ribeiro, 1998; Toledo et al., 2004).

intempérico propiciou a concentração de fosfatos e vermiculita e dos elementos nióbio, terras-raras e titânio no complexo Catalão I.

Vermiculitas macroscópicas, tais quais as encontradas no complexo Catalão I, tipicamente são trioctaédricas e possuem um intervalo restrito de capacidade de trocas ca- tiônicas (Basset, 1963). Em realidade, os mais importantes depósitos comerciais desse mineral estão associados a rochas máficas e ultramáficas, e o material que é explorado envolve tanto interestratificados vermiculita-biotita ou vermiculita-flogopita como vermiculitas propriamente ditas (Basset, 1963; Tsirambides e Michaelidis, 1999). 


\section{AMOSTRAGEM E MÉTODOS}

A área de amostragem desse trabalho encontra-se focada nas porções $\mathrm{N}$ e NE do complexo relativa às duas frentes de lavra exploradas pela Ultrafértil (Frentes 1 e 4; Figura 2b).

Considerando principalmente o estado de desagregação da rocha, a abundância relativa entre materiais sãos e alterados, a coloração e a concentração relativa de minerais micáceos e argilosos, em escala macroscópica, Ribeiro (1998) propõe um perfil esquemático com diferentes tipologias de minério correlacionável com os horizontes definidos por Oliveira e Imbernon (1998) e a partir do qual foram coletadas as amostras para esse estudo (Figura 3).
O horizonte Rocha Sã é composto por carbonatitos e flogopititos, em proporções relativamente variáveis, com foscoritos subordinados. O único ponto de amostragem onde ocorre este nível localiza-se na Frente 1 de lavra, onde se encontra grande quantidade de material brechado.

O horizonte Rocha Alterada ou Minério Sílico-Carbonatado, possui espessura variando em média de 10 a $20 \mathrm{~m}$, apresentando coloração esverdeada a acinzentada onde se pode ainda encontrar blocos de rocha fresca, representando a base do perfil de alteração. Macroscopicamente, podem ser identificados cristais de vermiculita (até $10 \mathrm{~cm}$ ), além de magnetita, apatita, carbonatos. Todas as estruturas e texturas observadas na rocha sã mantêm-se preservadas.

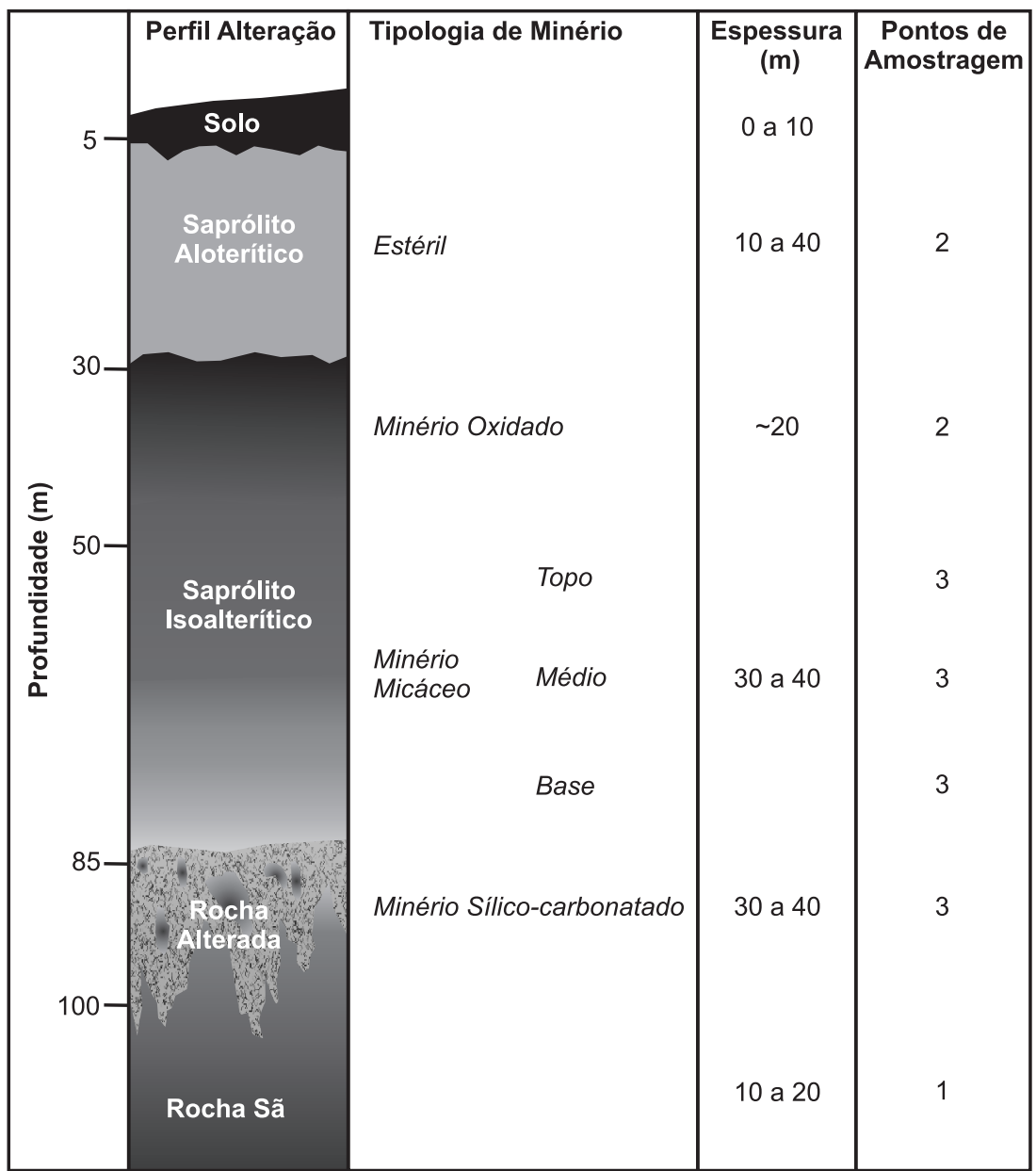

Figura 3. Modelo do perfil intempérico do Complexo Catalão I, segundo as diferentes tipologias de minério definidas pelo Setor de Geologia da Mina de Catalão I (Ribeiro, 1998; Toledo et al., 2004). Observam-se também os horizontes equivalentes estabelecidos por Oliveira e Imbernon (1998), além da amostragem utilizada nesse trabalho. 
O horizonte Saprólito Isoalterítico é subdividido nos níveis Minério Micáceo e Minério Oxidado, com espessura total variando entre 50 e $70 \mathrm{~m}$.

O nível Minério Micáceo com espessura de um modo geral variando na vertical entre 30 a $50 \mathrm{~m}$ é subdivido em base, médio e topo. Micáceo Base possui cor amarelo-alaranjada, com grande quantidade de flogopita e principalmente vermiculita, ainda mantendo preservadas parte das características do material original, principalmente no que diz respeito às estruturas e granulação média (ainda podem ser observados megacristais de vermiculita). Micáceo Médio possui coloração ocre-amarelada, ainda com grande quantidade de vermiculita preservada, porém já com diminuição na granulação desta, que agora é predominantemente média. Neste nível, pôde ser observado um aumento na quantidade de venulações preenchidas por quartzo. Micáceo Topo, de cor ocre escuro, apresenta diminuição na quantidade de filossilicatos, mantendo concentração relevante destes em seu início e baixa concentração no seu limite superior. Ocorre também diminuição na granulação, principalmente dos filossilicatos. No seu limite superior aumenta a quantidade de óxidos e quartzo e ocorre praticamente completa dissolução do carbonato.

No nível Minério Oxidado, de espessura aproximada de $20 \mathrm{~m}$ e coloração ocre escuro, já não é possível a identificação de filossilicatos a olho nu ou mesmo com auxílio de lupa. Além da grande quantidade de óxidos de Fe, há o aparecimento de óxidos de Mn neste nível. Também é encontrada textura do tipo boxwork, que deve representar a substituição de antigos veios carbonáticos por sílica.

O horizonte Saprólito Aloterítico ou Estéril com espessura de 10 a $40 \mathrm{~m}$, de coloração ora mais escura (amarronzada), ora alaranjada, ora ocre, é formado unicamente por material argiloso, de caráter aloterítico. O horizonte Solo varia em espessura de 0 a $10 \mathrm{~m}$, apresenta coloração vermelha, com composição rica em caolinita, e tem sua formação atribuída à contribuição de material alóctone de tipos rochosos mais ricos em alumínio (Oliveira e Imbernon, 1998).

A amostragem realizada para a maioria das amostras envolveu dois tipos: amostras de canaleta, onde em cada nível do perfil de alteração se coletou canaleta de aproximadamente $1 \mathrm{~m}$ de altura, gerando amostras de material friável de aproximadamente $3 \mathrm{~kg}$ cada; e, amostras indeformadas, que foram devidamente embaladas para preservar as características originais da porção do perfil a que pertencem.

Alíquotas extraídas a partir das amostras de canaleta foram utilizadas para obtenção de dados por difração de raios $\mathrm{X}$ pelo método do pó. As análises foram realizadas no Laboratório de Difração de raios X do Instituto de Geociências, com equipamento Siemens, modelo D5000, operando com tubo de cobre, sob as seguintes condições: voltagem de $40 \mathrm{KV}$, corrente de $40 \mathrm{~mA}, 2 \theta$ de 2 a $80^{\circ}$. Para a inter- pretação dos difratogramas foi utilizado o programa EVA 7.01 para Windows, tendo como banco de dados o PC-PDF (Powder Diffraction File - PDF for PC) produzido pelo International Center for Diffraction Data. A identificação dos filossilicatos por difração foi feita sobre amostra não orientada e orientada, glicolada e aquecida, segundo as técnicas padronizadas. Uma primeira etapa de reconhecimento dos minerais, sem nenhum tipo de separação mineralógica ou granulométrica, foi realizada a fim de se ter uma visualização geral da assembleia mineralógica. Com base nos resultados obtidos no estágio inicial, notou-se que muitas amostras apresentam quantidade relevante de material amorfo e fluorescente, que faz com que o background das análises seja elevado, tornando muitas vezes difícil a identificação de picos de forma significativa. Para sanar essa dificuldade e contar com dados com qualidade melhor, as amostras foram então divididas em 3 faixas granulométricas (por meio de técnicas de peneiramento): faixa acima de 100 mesh (acima de $0,149 \mathrm{~mm}$ ), faixa entre 100 e 200 mesh (entre 0,149 e $0,0745 \mathrm{~mm}$ ) e faixa entre 200 e 400 mesh (entre 0,0745 e $0,03725 \mathrm{~mm}$ ). Para cada uma destas faixas, ainda realizou-se a eliminação dos materiais ferromagnéticos das amostras, por meio de ímã de mão. Assim, para as 24 amostras analisadas foram determinados 72 difratogramas, sendo os melhores resultados (com maior intensidade de picos de filossilicatos e menor background) encontrados na faixa entre 100 e 200 mesh.

A partir das amostras indeformadas foram confeccionadas seções delgadas para análises microscópicas e de microssonda eletrônica. Foram estudadas 18 lâminas delgadas correspondentes aos litotipos encontrados no ponto de afloramento de rocha sã e do horizonte Rocha Alterada. Também, analisaram-se 10 lâminas delgadas de amostras representativas dos principais níveis do perfil intempérico que foram impregnadas e estas permitiram uma melhor visualização de como o processo de vermiculitização atua no contexto deste perfil laterítico no horizonte Saprólito Isoalterítico.

A caracterização química dos principais minerais micáceos do Complexo Catalão I foi realizada no Laboratório de Microssonda Eletrônica do Departamento de Mineralogia e Geotectônica de Instituto de Geociências da USP, empregando-se instrumental de fabricação JEOL modelo JXA-8600 equipado com cinco espectrômetros dispersivos (WDS) com 5 pares de cristais $\underline{\mathrm{TAP}} / \mathrm{STE}, \underline{\mathrm{TAP}} / \mathrm{PET}$, $\underline{\text { LIF/PET, PET/LIF e LIF/PET respectivamente (os cristais }}$ sublinhados são aqueles utilizados nas rotinas analíticas preestabelecidas no laboratório) e automatizados com um sistema TRACOR - Voyager 4.1 da NORAN Instruments. As determinações foram efetuadas em seções delgadas polidas, metalizadas com uma película de carbono $(\sim 25 \mathrm{~nm})$ em evaporador AUTO 306 da EDWARDS. As condições analíticas utilizadas para os minerais foram: $15 \mathrm{kV}$ para 
potencial de aceleração; 20 ๆA para corrente do feixe eletrônico; e diâmetro do feixe $5 \mu \mathrm{m}$. Os tempos máximos de integração das contagens de pulsos nos contadores variaram de 10" para Ca e Si até 50" para Sr. Os dados químicos das análises realizadas são apresentados como porcentagem em peso de óxidos e como fórmulas químicas estruturais. A única rotina analítica empregada é a própria para micáceos preestabelecida no laboratório.

As fórmulas estruturais das flogopitas e tetraferriflogopitas foram calculadas segundo os procedimentos adotados em Araújo (1996) e Brod et al. (2001), entendendo-se que as deficiências de $\mathrm{Si}$ e ${ }^{\mathrm{IV}} \mathrm{Al}$ do sítio tetraédrico são completamente preenchidas por $\mathrm{Fe}^{3+}$, e o restante do $\mathrm{Fe}$ calculado como $\mathrm{Fe}^{2+}$ no sítio octaédrico. Os resultados são apresentados na base de 24 oxigênios, com $\mathrm{H}_{2} \mathrm{O}$ calculado por estequiometria. Já para os produtos da alteração vermiculítica, as fórmulas estruturais foram calculadas na base anidra de 22 oxigênios, sendo todo o $\mathrm{Fe}$ calculado como $\mathrm{Fe}^{3+}$, e assumindo-se que os sítios octaédricos foram completamente ocupados. Assim, quando a soma dos cátions octaédricos excede 6 , o excesso no conteúdo de $\mathrm{Mg}$ é associado ao sítio interfoliar, em processo usual para análises desse mineral (Foster, 1963; Tsirambides e Michaelidis, 1999).

\section{RESULTADOS}

\section{Difração de raios $X$}

Os principais filossilicatos identificados por difratometria de raios $\mathrm{X}$ em amostras dos diferentes horizontes intempéricos do Complexo Catalão I são vermiculita e minerais interestratificados mica-vermiculita (Figura 4).

A vermiculita é caracterizada por apresentar valores de $d$ (distância interplanar) entre 14 e 15 Å em difratogramas sobre lâminas em condições normais e glicoladas. Esse argilomineral se distingue dos argilominerais do grupo da esmectita, que se expandem sob etilenoglicol, aumentando seus valores de $d$ para $17 \AA$, e também da clorita, que apresenta picos proeminentes para valores de $d$ iguais a $7 \AA$ ). Uma característica anormal identificada em algumas análises é a permanência de $d$ entre 14 e $15 \AA$ após o aquecimento das lâminas, discrepante do comportamento usual indicado pelo deslocamento deste pico para 12 - $10 \AA$, associado a uma contração ao aquecimento de vermiculitas saturadas em $\mathrm{K}$. Uma composição altamente magnesiana, que eleva a temperatura de perda do cátion interfoliar, ao invés de vermiculitas aluminosas normalmente utilizadas nos padrões de referência, poderia explicar tal comportamento, assim como proposto por Guimarães e Lenharo (2002). Segundo Moore e Reynolds (1989), esta feição sugere que, além de cátions hidratados, como o $\mathrm{Mg}$ e $\mathrm{Ca}$, essas vermiculitas podem pos- suir folhas incompletas de complexos "hidroxi-cátions" no sítio interfoliar, como o $\mathrm{Al}$.

Minerais interestratificados são formados pelo empilhamento de folhas de diferentes filossilicatos, e têm os valores de $d$ dependentes do tipo de folha e da organização do empilhamento. Rectorita e hidrobiotita, minerais que representam o empilhamento regular de um número idêntico de folhas por mica (ou ilita)-esmectita e mica-vermiculita, respectivamente, foram utilizados como referência para a identificação desses minerais.

Interestratificados não expansivos com as características de hidrobiotita são identificados na maioria das amostras e apresentam reflexões que mantêm valores de $d$ próximos a $25 \AA$ e $12,5 \AA$ em condições normais e mesmo após a glicolação, indicando que não contêm esmectita. Com o aquecimento, as reflexões acima referidas desaparecem e surgem reflexões em $d$ próximos a $10 \AA$ A típico de micas. Assim, esses minerais são interpretados como interestratificados de vermiculita e flogopita. Muitos interestratificados mantêm, mesmo com aquecimento, picos acima de $24 \AA$ após o aquecimento, comportamento que sugere uma proporção maior de vermiculita no interestratificado (Guimarães e Lenharo, 2002).

Localmente, apenas em poucas amostras são identificados interestratificados expansivos com as características de rectorita, que são evidenciados por apresentar valores de $d$ en-

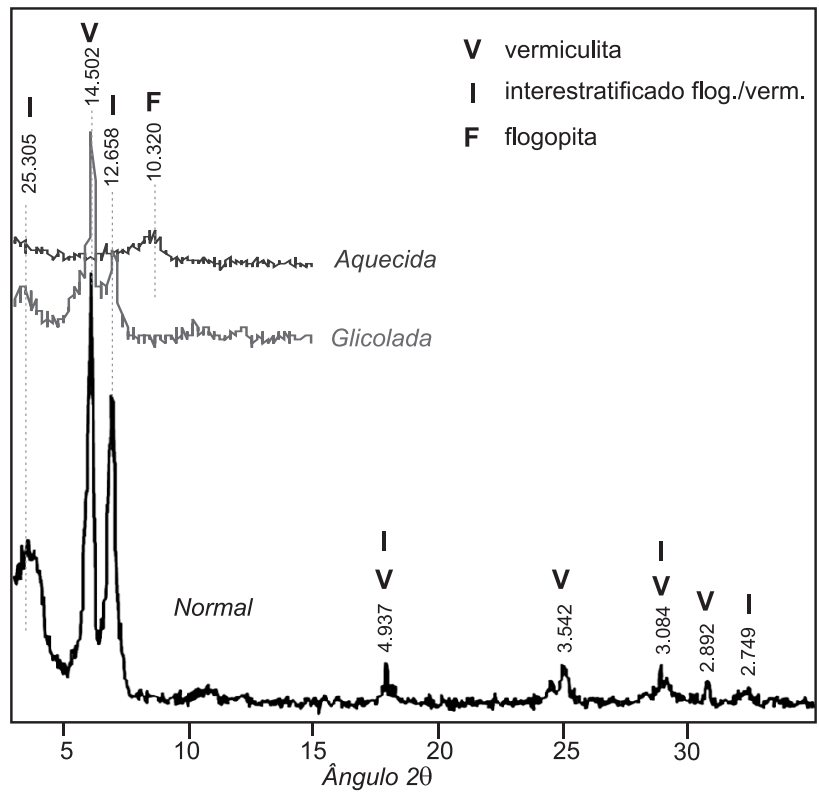

Figura 4. Difratograma de raios $X$ em amostra do horizonte Rocha Alterada exemplificando os principais picos de vermiculita e interestratificado flogopita/vermiculita do Complexo Catalão I. 
tre 24 e $25 \AA$ e 12 e 13 An nas lâminas sob condições normais, com aumento para 25 - $27 \AA$ e 13 - $14 \AA$ em lâminas glicoladas. Nas lâminas aquecidas, estas reflexões desaparecem, porém surgindo novas correspondentes a $10 \AA$, semelhantes a micas e sugerindo interestratificados esmectita-flogopita.

Congruentes com esses resultados são os dados difratométricos obtidos por Guimarães e Lenharo (2002), em estudo restrito ao nível Minério Micáceo do horizonte Saprólito Isoalterítico.

Também de forma local, em poucas amostras, há identificação de esmectita, caracterizada por picos de $14 \AA \mathrm{sob}$ condições normais, e expandindo estas reflexões para $17 \AA$ sob condições glicoladas, diferenciando-se assim das vermiculitas. Após aquecimento, são geradas novas reflexões de $d$ a $10 \AA$, desaparecendo as anteriores. Significativamente, a presença deste mineral se dá em níveis superiores do perfil (Micáceo Topo e Oxidado), ocorrendo em muitos casos associada com a vermiculita. Tal feição sugere para a esmectita uma formação pontual ou indicativa de contribuição supérgena (Imbernon, 1993), onde argilominerais como caolinita e esmectita preencheriam veios anteriores de material carbonático, ou de processo de esmectitização de vermiculitas (Wilson, 1999).

Em algumas amostras, sob condições normais, observa-se a reflexão para valores de $d$ próximos a $10 \AA$, atribuída à flogopita. A intensidade muito baixa desses picos é indicativa da baixa concentração relativa desse mineral, podendo representar relíctos preservados de alteração.

De aspecto relevante, os difratogramas das amostras a partir de Micáceo Topo tendem a apresentar menor intensidade relativa dos picos de micáceos, mesmo nas faixas granulométricas em que estes picos são mais pronunciados. Tal fato pode ser explicado por uma menor cristalinidade deste mineral em relação aos outros minerais da amostra ou mesmo por uma menor concentração nos níveis superiores, indicando a ação mais intensa do intemperismo a partir desse nível.

Além dos filossilicatos, como principais minerais que ocorrem na maioria das amostras, tem-se apatita, goethita e quartzo. Caolinita, gibbsita, anatásio, crandalita, dolomita e barita ocorrem subordinadamente em algumas amostras. Na grande maioria dos difratogramas, há maior intensidade dos picos de $14 \AA$ sobre os picos de $24-25 \AA$, podendo indicar uma maior concentração relativa ou uma maior cristalinidade e ordenamento da vermiculita.

\section{Petrografia}

\section{Horizonte Rocha Sã}

Nas rochas flogopitíticas, ocorrem cristais de flogopita com granulação atingindo até $2,5 \mathrm{~mm}$. Apresentam nú- cleos com pleocroísmo normal, nas tonalidades de marrom claro a marrom escuro, e bordas formadas por tetraferriflogopita (Figura 5a). Nessas rochas, veios carbonáticos parecem condicionar sua formação, gerando bordas caracterizadas por apresentar pleocroísmo invertido, variando de incolor ou laranja claro para laranja ou vermelho intenso. Essas bordas possuem contato geralmente brusco com as regiões do cristal formadas por flogopita com pleocroísmo normal. Cristais de menor granulação $(0,03 \mathrm{~mm})$ na matriz apresentam-se totalmente transformados para este tipo textural.

Em rochas ultramáficas metassomatizadas, formadas por flogopita, olivina, carbonatos, perovskita, opacos e apatita encontram-se cristais praticamente tabulares de flogopita, de forma euédrica a subédrica, dimensão média 0,25 mm, pleocroísmo normal, variando de alaranjado a marrom em sua coloração. São intersticiais em relação à olivina e aos carbonatos presentes, sugerindo textura reliquiar para olivinas, com flogopita sendo formada por meio da reação com este mineral. Nestas rochas, a textura pode ser definida como kelifítica, assim como mostra a Figura 5b. Este tipo de flogopita também possui transformação para tetraferriflogopita, ocorrendo esta predominantemente nas bordas dos cristais, com pleocroísmo invertido, embora alguns cristais já se encontrem inteiramente transformados.

Em realidade, a tetraferriflogopita parece ter intrínseca relação com os estágios carbonatíticos. Há cristais em lâminas de rochas carbonatíticas que ocorrem isolados e apresentam-se totalmente tetraferriflogopitizados, não se sabendo dizer se estes foram formados no próprio magma carbonatítico ou se são produtos da transformação de cristais preexistentes (Figura 5c). Muitos destes cristais, inclusive, sugerem diferentes estágios de tetraferriflogopitização, conforme indicado pelas cores de pleocroísmo geradas (partes alaranjadas e avermelhadas em contato predominantemente brusco no sentido da maior absorção da luz). Estes estágios de tetraferriflogopitização são compatíveis com as seguidas injeções de magma carbonatítico, aos quais estas micas parecem estar ligadas.

\section{Horizonte Intempérico Rocha Alterada}

Neste nível, onde o processo de vermiculitização é proeminente, consegue-se dizer de qual tipo de rocha do complexo estas são derivadas, uma vez que o grau de alteração ainda não é tão pronunciado.

Em rochas já parcialmente alteradas, a alteração de flogopita e tetraferriflogopita é indicada por cristais com pleocroismo normal, com núcleo variando de coloração marrom a marrom clara e bordas de coloração bege ou incolor, representando o início do processo vermiculitização. Nenhum traço de tetraferriflogopita é preservado. In- 



Figura 5. Aspectos microscópicos gerais das diferentes paragêneses de minerais micáceos e dos produtos de alteração vermiculítica no perfil intempérico do complexo Catalão I. Micáceos em: A. flogopititos, B. rocha ultramáfica metassomatizada, C. carbonatito. Produtos de alteração vermiculítica em: D. nível Rocha Alterada, E. nível Micáceo Base, F. nível Micáceo Médio, G. nível Micáceo Topo e H. nível Oxidado. Polarizadores paralelos. Abreviações: $\mathbf{F}=$ flogopita, $\mathbf{T f f}=$ tetraferriflogopita, $\mathbf{P V}=$ produtos da vermiculitização, $\mathbf{P v r}=$ produtos de vermiculitização - recobrimento superficial, $\mathbf{C}=$ carbonato, $\mathrm{OI}=$ olivina. No nível oxidado são apenas encontrados pseudomorfos de filossilicatos, que estão circulados. 
clusive, em muitos cristais não é observado nenhum tipo de pleocroismo. Cristais totalmente vermiculitizados apresentam hábito placoide, birrefringência baixa, ora incolor ora de coloração amarelada, com dimensões desde submilimétricas até centimétricas (Figura 5d).

Principalmente nesse horizonte alguns cristais de vermiculita possuem alteração para clorita em suas bordas, porém, essa alteração é geralmente bastante restrita e de granulação extremamente fina. Também, em rochas carbonatíticas não alteradas, a clorita é encontrada junto de cristais de tetraferriflogopita da matriz.

\section{Horizonte Saprólito Isoalterítico - Nível Intempérico Micáceo Base}

Em comparação com o nível anterior, observa-se que as micas já vermiculitizadas (coloração amarelada e bege com birrefringência baixa) agora apresentam nos contatos entre grãos material de cor marrom, indicativo de percolação de óxidos e hidróxidos de Fe. Entre os cristais da matriz, inclusive, nota-se que muitos já estão totalmente alterados para esta cor (Figura 5e).

Interessante notar que a heterogeneidade no desenvolvimento do perfil ocorre inclusive na escala microscópica. Uma das lâminas analisadas nesse nível apresenta, em sua extensão de $3,5 \mathrm{~cm}$, as principais variações de micáceos alterados que ocorrem desde o nível Rocha Sã até Micáceo Topo. Este tipo de alteração que abrange em microescala as várias tipologias do perfil intempérico pode ser explicada por microfraturas e vazios estruturais que condicionariam uma ação intempérica mais intensa nestas regiões.

\section{Horizonte Saprólito Isoalterítico - Nível Intempérico Micáceo Médio}

Neste nível intempérico, pode-se notar que as micas de cor marrom predominam sobre as de cor amarelada (Figura 5f). Tal feição é indicativa da percolação de óxidos e hidróxidos de Fe sobre todo o material. Entende-se que esta coloração represente tanto neste quanto nos anteriores níveis apenas uma impregnação superficial, não modificando ou alterando a estrutura destes minerais.

Em análises macroscópicas, nota-se nítida mudança de cor entre as amostras do Nível Rocha Alterada (esverdeado) e os Níveis de Micáceo Base (alaranjado), Médio (ocre amarelado) e Topo (cor ocre escuro). Estas cores coincidem com a quantidade de material marrom (principalmente hidróxidos de $\mathrm{Fe}$ ) encontrado nas lâminas. Assim, entende-se que, da base para o topo, a quantidade de percolação de hidróxidos de $\mathrm{Fe}$ aumenta progressivamente. Além disso, a diferença de coloração pode também estar associada a diferentes tipos de hidróxidos e óxidos; ala- ranjado, ocre amarelado e ocre escuro poderiam indicar produtos amorfos (como ferrihidrita), goethita e hematita, respectivamente.

\section{Horizonte Saprólito Isoalterítico - Nível Intempérico Micáceo Topo}

No nível Micáceo Topo, observa-se o aumento na quantidade hidróxidos de $\mathrm{Fe}$ em relação à Micáceo Médio (Figura $5 \mathrm{~g}$ ). Na matriz, muitos cristais de mica apresentam cor marrom escura e mesmo coloração preta, sugestivo não só de um recobrimento superficial de cristais de vermiculita, mas de alterações mais intensas, perdendo-se as características de filossilicatos e restando apenas pseudomorfos.

\section{Horizonte Saprólito Isoalterítico - Nível Intempérico Minério Oxidado}

Neste nível, ocorrem apenas pseudomorfos de mica, percebidos estes pelos planos de clivagem bem definidos, já substituídos por óxidos/hidróxidos de Fe e também caolinita. Este é o último nível com características isoalteríticas (Figura 5h).

\section{Química Mineral}

\section{Flogopita e Tetraferriflogopita em Rocha Sã}

Os resultados (Tabela 1) mostram que todos os cristais de mica de Rocha Sã correspondem quimicamente à flogopita, tendo em vista que a relação $\mathrm{Mg}$ :Fe é maior que 2:1 (Deer, Howie, Zussman, 1992).

Pode-se notar que as diferenças petrográficas correspondem às diferenças químicas destes minerais. Na flogopita dos flogopititos, nota-se que o sítio tetraédrico é ocupado por $\mathrm{Si}(5,263$ - 5,858 a.f.u.), $\mathrm{Al}(1,421$ - 2,022 a.f.u.) e parte do $\mathrm{Fe}^{3+}$ ou todo $\mathrm{Fe}(0,396$ - 0,635) ocupam o sítio tetraédrico. O sítio octaédrico é preenchido quase totalmente por $\operatorname{Mg}(5,271$ - 5,867 a.f.u.) ocorrendo subordinadamente $\mathrm{Ti}\left(0,201-0,723\right.$ a.f.u.), $\mathrm{Fe}^{2+}$ (até 0,1 a.f.u.), e $\mathrm{Mn}$ (até 0,034 a.f.u.). Os sítios interfoliares são ocupados especialmente por $\mathrm{K}(1,78$ - 1,92 a.f.u.), e traços de $\mathrm{Ba}$ (até 0,041 a.f.u.), $\mathrm{Na}$ (até 0,017 a.f.u.) e Ca (até 0,013 a.f.u.)

Na flogopita da rocha ultramáfica metassomatizada, temse a ocupação do sítio tetraédrico por $\mathrm{Si}$ (5,436 - 5,64 a.f.u.), $\mathrm{Al}\left(1,985\right.$ - 2,136 a.f.u.) e parte do $\mathrm{Fe}^{3+}$ ou todo $\mathrm{Fe}(0,372$ 0,474 a.f.u.). O sítio octaédrico é preenchido principalmente por $\mathrm{Mg}(4,169$ - 4,548 a.f.u.) com quantidades relevantes de $\mathrm{Fe}^{2+}(0,737-0,921$ a.f.u.), Ti (até 0,6 a.f.u.) e $\mathrm{Mn}$ (até 0,013 a.f.u.). Os sítios interfoliares são ocupados essencialmente por $\mathrm{K}$ (até 1,839 a.f.u.) com traços de $\mathrm{Ba}$ (até 0,047 a.f.u.), $\mathrm{Na}$ (até 0,011 a.f.u.) e Ca (até 0,012 a.f.u.). 


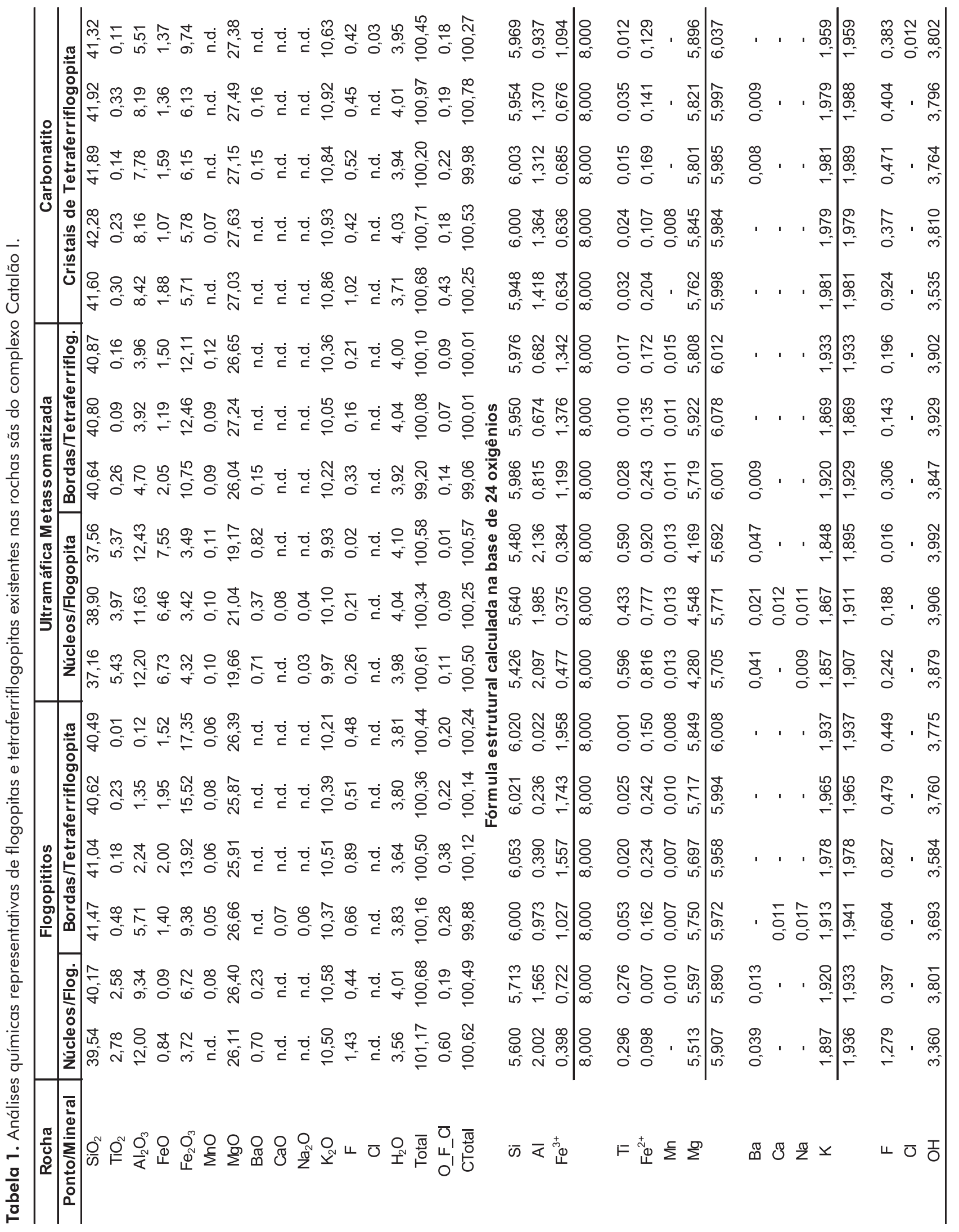


Nas diferentes ocorrências de tetraferriflogopita, o sítio tetraédrico é ocupado por todo $\mathrm{Si}(5,862$ - 6,053 a.f.u.), $\mathrm{Al}$ $(0,017-1,818$ a.f.u. $)$ e parte do $\mathrm{Fe}^{3+}$ ou todo $\mathrm{Fe}(0,223-$ 1,939 a.f.u.). O sítio octaédrico é preenchido quase totalmente por $\operatorname{Mg}(5,606$ - 5,939 a.f.u.) ocorrendo subordinadamente $\mathrm{Fe}^{2+}(0,089$ - 0,332 a.f.u.), Ti (até 0,15 a.f.u.), e $\mathrm{Mn}$ (até 0,017 a.f.u.). Os sítios interfoliares são ocupados especialmente por $\mathrm{K}(1,869$ - 1,981 a.f.u.), e traços de Ba (até 0,046 a.f.u.), $\mathrm{Na}$ (até 0,017 a.f.u.) e $\mathrm{Ca}$ (até 0,011 a.f.u.).

A Figura 6a apresenta a distribuição de $\mathrm{Al}, \mathrm{Mg}$ e Fe para as flogopitas de Catalão. Nota-se que as análises de flogopitas com pleocroismo normal são plotadas próximas à linha da série flogopita-anita, indicando deficiência em Al. Nota-se também o intervalo de composição ao longo da linha flogopita-tetraferriflogopita. Foi em Catalão I que Araújo (1996) registrou a primeira ocorrência conhecida da série completa flogopita-tetraferriflogopita.

De modo geral, nota-se que as principais trocas catiônicas desses minerais estão relacionadas ao sítio tetraédrico, e que a composição química destas é intrinsecamente relacionada com suas características ópticas. Brod et al. (2001) baseado em critérios químicos e ópticos, dividem essas flogopitas em dois grupos: 1) com teores relativamente elevados de $\mathrm{Al}$ e Ti e relativamente baixos de $\mathrm{Si}, \mathrm{Mg}$ e $\mathrm{Fe}_{\mathrm{T}}$, com pleocroísmo normal e 2) com teores elevados de $\mathrm{Fe}_{\mathrm{T}}$ e $\mathrm{Si}$ e baixos de $\mathrm{Al}$ e Ti com pleocroismo invertido.

A variação composicional de $\mathrm{Si}, \mathrm{Al}$ e Fe por toda a série flogopita-tetraferriflogopita e suas relações com pleocroismo invertido são apresentados na Figura 7. Nas flogopitas, há uma correlação entre $\mathrm{Si}$ e $\mathrm{Al}$ no sítio tetraédrico, enquanto para as tetraferriflogopitas (com valores de $\mathrm{Al}$ menores 1,5 a.f.u.) esta correlação desaparece e uma forte correlação entre $\mathrm{Al}$ e $\mathrm{Fe}^{3+}$ prevalece, congruente com os dados de Brod et al. (2001).

\section{Vermiculita e Interestratificado dos diversos Níveis Intempéricos}

As Tabelas 2 e 3 apresentam os resultados analíticos obtidos para os produtos de alteração vermiculítica nos diversos níveis de alteração. Para todos os casos o Fe foi calculado a partir de $\mathrm{Fe}_{2} \mathrm{O}_{3}$, dado que o principal produto final de alteração é a vermiculita e o $\mathrm{Fe}^{3+}$ é um de seus principais constituintes.

As características químicas apresentadas pelos filossilicatos desde o horizonte Rocha Alterada até o nível Micáceo Topo do horizonte Saprólito Isoalterítico variam predominantemente nas concentrações de $\mathrm{K}, \mathrm{Mg}, \mathrm{Ca}, \mathrm{Fe}$ e Ti, porém não apresentando diferenças composicionais significativas entre os diferentes níveis intempéricos. Esses elementos possuem variações extremas, ocorrendo tipos enriquecidos, intermediários e extremamente empobrecidos. Em relação
A

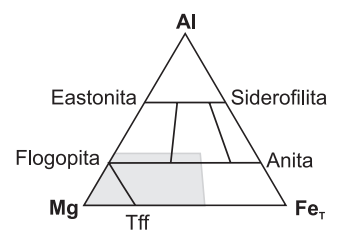

Flogopititos

Flogopita (Núcleo)

Tetraferriflogopita (Borda)

Ultramáficas Metasomatizadas

$\square$ Flogopita (Núcleo)

- Tetraferriflogopita (Borda)

Carbonatitos

Tetraferriflogopita

(Núcleo e Borda)
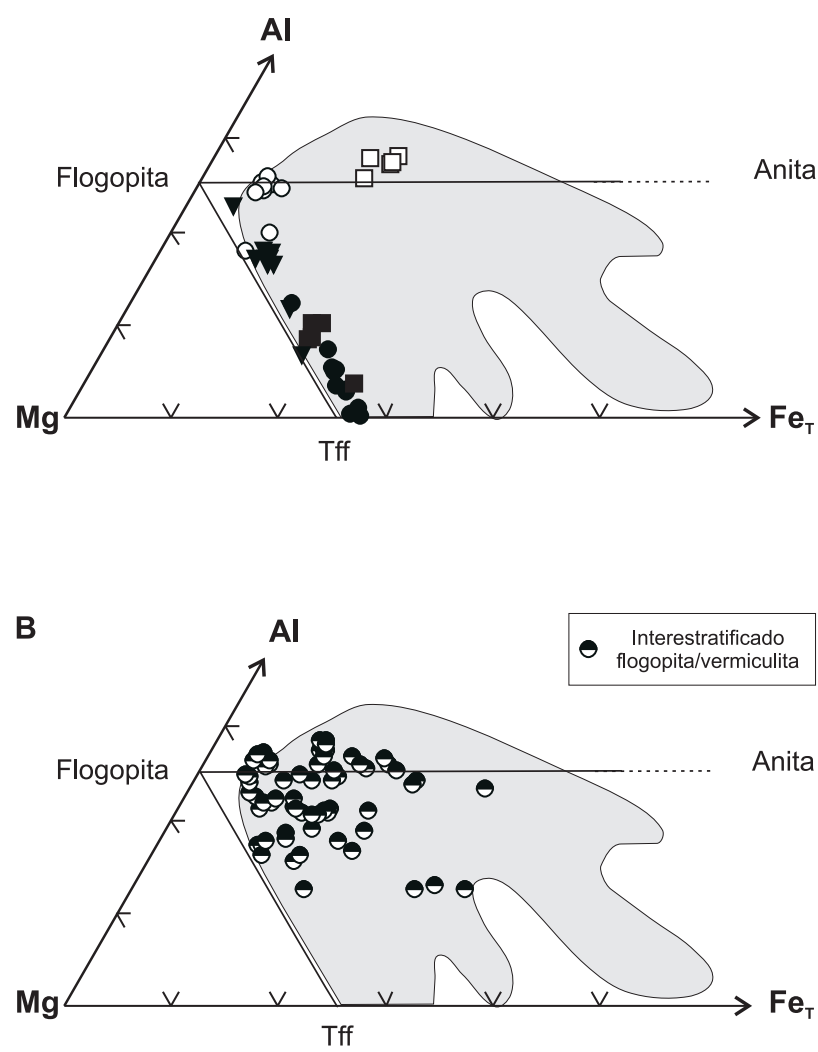

C

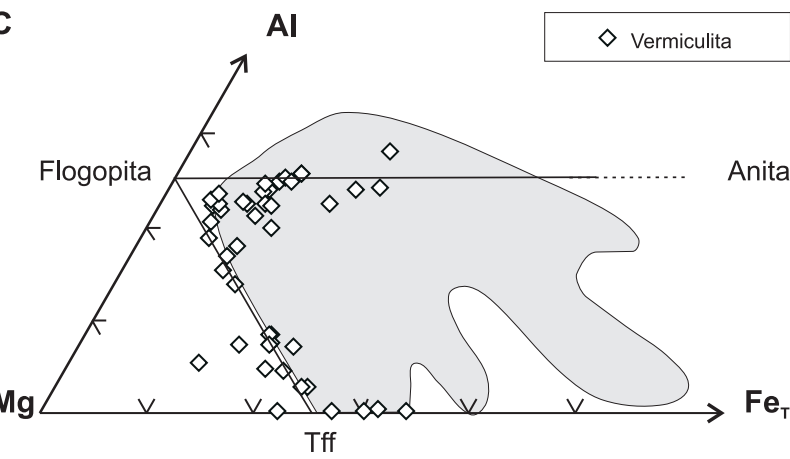

Figura 6. Distribuição de $\mathrm{Al}, \mathrm{Mg}$ e $\mathrm{Fe}_{\text {total }}$ (a.f.u.) nos filossilicatos do complexo Catalão I. A. Flogopitas e tetraferriflogopitas. B. Interestratificado flogopita/vermiculita. C. Vermiculita. O campo em cinza apresenta os dados e trends obtidos por Brod et al. (2001) para flogopitas e tetraferriflogopitas dessa ocorrência. 


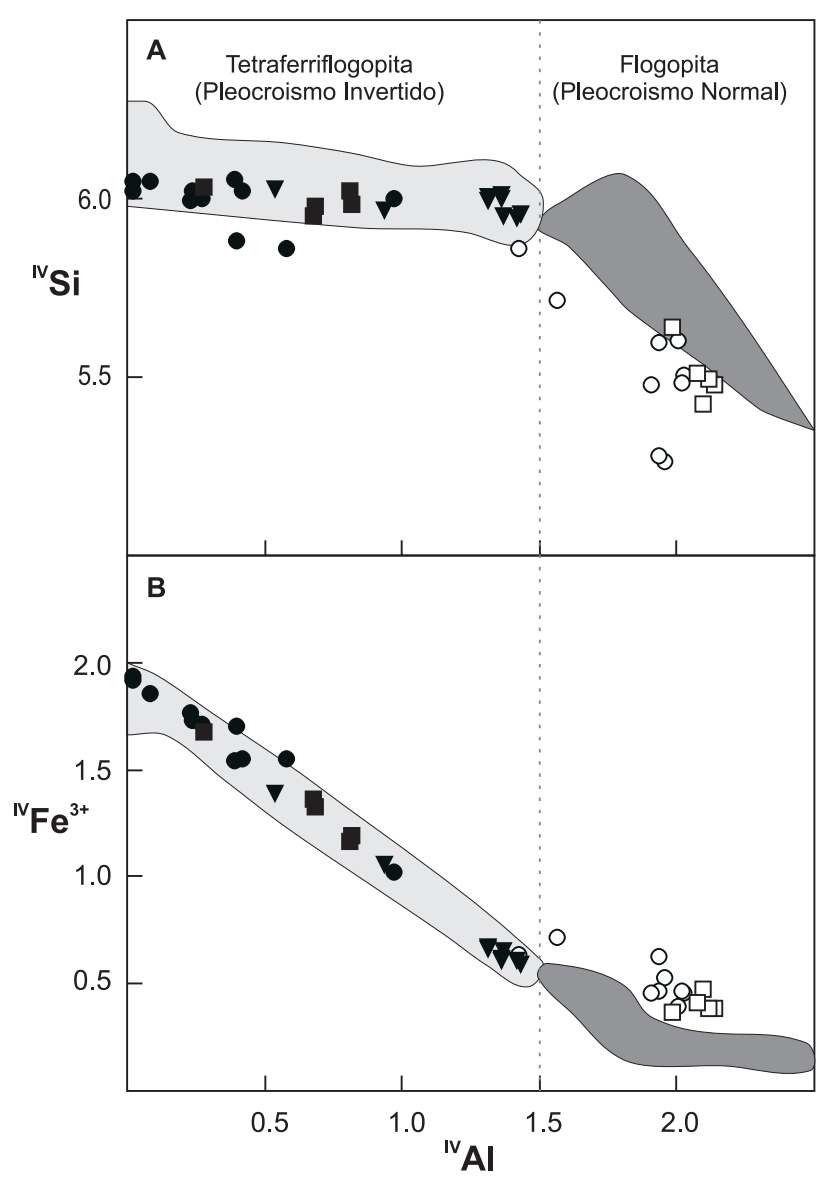

Figura 7. Variações de Al vs. A. Si e B. $\mathrm{Fe}^{3+}$ (a.f.u.) no sítio tetraédrico das flogopitas de Catalão I. Em cinza, apresentam-se os campos de Brod et al. (2001).

às análises das flogopitas, as principais alterações intempéricas dizem respeito à diminuição significativa na concentração de $\mathrm{K}$ e aumento progressivo de $\mathrm{Mg}$ e Ca.

Especialmente as relações de concentração entre $\mathrm{K}$ e $\mathrm{Mg}$ permitem uma divisão dos dois grupos típicos de produtos da alteração vermiculítica, conforme apresenta a Figura 8. O primeiro grupo é definido por valores de $\mathrm{K}$ no intervalo principal entre 0,775 a 1,35 a.f.u. e valores de $\mathrm{Mg}$ via de regra menores que 6 a.f.u., correspondendo ao interestratificado flogopita-vermiculita, e o segundo é definido por valores de $\mathrm{K}$ menores que 0,225 a.f.u. e $\mathrm{Mg}$ maior que 5,6 a.f.u., correspondendo à vermiculita (Figura 8a; Foster, 1963; Guimarães e Lenharo, 2002).

As concentrações de $\mathrm{Si}$, Al (Figura 8b), Ti e Fe (Figuras $9 \mathrm{a}$ e $9 \mathrm{~b}$ ) nesses produtos de alteração acompanham o mesmo campo de variação observado para flogopitas e tetraferriflogopitas do maciço. Já as concentrações de Ca tanto de vermiculitas quanto de interestratificados (Figura 8c) aumentam significativamente em relação às flogopitas e tetraferriflogopitas de rocha sã, variando desde traços até 0,2 a.f.u. para a maioria dos dados, porém atingindo até 0,5 a.f.u. em alguns casos, e guardam estreita correlação com a diminuição dos teores de K. As concentrações de $\mathrm{Mg}$ aumentam significativamente nas vermiculitas em relação a flogopitas e interestratificados pois, dada a gradual lixiviação de $\mathrm{K}$ da flogopita inicial somada à deficiência de cargas das substituições de $\mathrm{Si}$ por $\mathrm{Al}$ e $\mathrm{Fe}^{3+}$, há uma compensação de cargas para a estabilidade mineral que envolve, entre outros fatores, o aumento da concentração do Mg no sítio octaédrico e a acomodação de cátions divalentes no sítio interfoliar, especialmente $\mathrm{Mg}$ e subordinadamente o Ca. (Foster, 1963; Deer, Howie, Zussman, 1992; Tsirambides e Michaelidis, 1999; Guimarães e Lenharo, 2002). Pode-se notar que, no caso das vermiculitas, o Mg e o Ca são os principais responsáveis pelo preenchimento do sítio interfoliar. Ressalte-se também o início da acomodação de $\mathrm{Mg}$ nesse sítio já nos interestratificados, embora ainda em concentrações subordinadas ao $\mathrm{K}$.

Ainda quanto aos teores de $\mathrm{Al}, \mathrm{Fe}$ e $\mathrm{Mg}$, as Figuras $6 \mathrm{~b}$ e 6c apresentam os seus principais intervalos composicionais obtidos para interestratificados e vermiculitas, respectivamente. Pode-se notar que os produtos de vermiculitização seguem os trends associados à série flogopita-anita e à série flogopita-tetraferriflogopita, da mesma forma que as variações gerais de flogopitas do complexo definidas por Brod et al. (2001). Nesse sentido, nota-se que especialmente as vermiculitas apresentam o trend associado à série flogopita-tetraferriflogopita. Possivelmente tal feição sugira que o processo de vermiculitização seja mais intenso em tetraferriflogopitas que nas flogopitas do complexo, uma vez que os interestratificados são produtos intermediários desse processo e tendem a seguir à série flogopita-anita.

Estes dois produtos principais do processo de vermiculitização ocorrem em todos os níveis intempéricos (até Micáceo Topo) com as mesmas características químicas, embora petrograficamente a percolação de hidróxidos de Fe tenha conduzido a características texturais distintas entre os níveis.

A partir do Nível Micáceo Topo as transformações passam a ser mais intensas, sendo encontrados pseudomorfos de filossilicatos, caracterizados pela elevada concentração relativa de Fe e com fechamento bastante irregular, indicando lixiviação dos principais elementos (Al, Si e Mg principalmente).

No nível Oxidado, topo da porção isoalterítica do perfil, não ocorrem mais as vermiculitas ou os interestratificados. Apenas ocorrem pseudomorfos de filossilicatos, que foram identificados nas análises petrográficas. A composição destes varia significativamente de um cristal para outro: ora são constituídos por $\mathrm{Si}$, ora predominantemente 
Tabela 2. Análises químicas representativas de interestratificado flogopita/vermiculita do perfil intempérico de Catalão I.

\begin{tabular}{|c|c|c|c|c|c|c|c|c|c|c|}
\hline Nível & \multicolumn{3}{|c|}{ Rocha Alterada } & \multicolumn{3}{|c|}{ Micáce o Base } & \multicolumn{4}{|c|}{ Micáceo Médio } \\
\hline Mineral & \multicolumn{3}{|c|}{ Interestratificado } & \multicolumn{3}{|c|}{ Interes tratificado } & \multicolumn{4}{|c|}{ Interestratificado } \\
\hline $\mathrm{SiO}_{2}$ & 40,19 & 39,77 & 37,50 & 43,78 & 31,90 & 40,32 & 40,81 & 41,49 & 41,56 & 24,08 \\
\hline $\mathrm{TiO}_{2}$ & 4,04 & 2,04 & 2,23 & 0,38 & 2,16 & 1,46 & 0,60 & 0,27 & 1,12 & 3,11 \\
\hline $\mathrm{Al}_{2} \mathrm{O}_{3}$ & 11,99 & 12,50 & 12,38 & 6,81 & 11,15 & 9,25 & 9,56 & 7,35 & 10,54 & 8,99 \\
\hline $\mathrm{Fe}_{2} \mathrm{O}_{3}$ & 4,35 & 8,08 & 7,42 & 9,43 & 22,08 & 7,36 & 10,18 & 9,89 & 7,63 & 25,90 \\
\hline $\mathrm{MnO}$ & 0,05 & 0,14 & 0,09 & 0,06 & 0,07 & 0,08 & 0,16 & 0,14 & 0,07 & 0,05 \\
\hline $\mathrm{MgO}$ & 25,19 & 23,93 & 25,73 & 24,53 & 19,63 & 23,19 & 23,60 & 25,04 & 25,09 & 14,65 \\
\hline $\mathrm{BaO}$ & 0,26 & 0,25 & 0,39 & n.d. & 0,53 & 0,13 & 0,30 & n.d. & 0,23 & 0,26 \\
\hline $\mathrm{CaO}$ & 0,52 & 0,59 & 0,71 & 0,86 & 0,34 & 0,65 & 0,11 & 0,29 & 0,34 & 0,68 \\
\hline $\mathrm{Na}_{2} \mathrm{O}$ & 0,05 & n.d. & n.d. & 0,05 & n.d. & n.d. & n.d. & n.d. & 0,04 & n.d. \\
\hline $\mathrm{K}_{2} \mathrm{O}$ & 5,41 & 4,86 & 2,60 & 4,60 & 4,57 & 4,56 & 4,78 & 4,70 & 4,51 & 3,69 \\
\hline $\mathrm{F}$ & 0,39 & 0,27 & 0,32 & 0,96 & 0,43 & 1,16 & 0,88 & 0,92 & 0,77 & 0,76 \\
\hline $\mathrm{Cl}$ & n.d. & 0,02 & 0,02 & n.d. & 0,02 & 0,06 & n.d. & n.d. & n.d. & 0,19 \\
\hline Total & 96,47 & 96,50 & 93,35 & 95,20 & 96,61 & 91,65 & 94,65 & 93,82 & 95,71 & 85,32 \\
\hline O_F_Cl & 0,17 & 0,12 & 0,14 & 0,40 & 0,18 & 0,50 & 0,37 & 0,39 & 0,32 & 0,36 \\
\hline CTotal & 96,30 & 96,38 & 93,21 & 94,80 & 96,43 & 91,15 & 94,28 & 93,43 & 95,39 & 84,96 \\
\hline \multicolumn{11}{|c|}{ Fórmula es trutural calculada na base anidra de 22 oxigênios } \\
\hline $\mathrm{Si}$ & 5,729 & 5,702 & 5,512 & 6,363 & 4,857 & 6,083 & 6,004 & 6,152 & 5,980 & 4,305 \\
\hline $\mathrm{Al}$ & 2,013 & 2,110 & 2,143 & 1,166 & 1,999 & 1,643 & 1,656 & 1,284 & 1,786 & 1,892 \\
\hline \multirow[t]{2}{*}{$\mathrm{Fe}^{3+}$} & 0,258 & 0,188 & 0,345 & 0,471 & 1,144 & 0,274 & 0,340 & 0,564 & 0,234 & 1,803 \\
\hline & 8,000 & 8,000 & 8,000 & 8,000 & 8,000 & 8,000 & 8,000 & 8,000 & 8,000 & 8,000 \\
\hline $\mathrm{Ti}$ & 0,433 & 0,220 & 0,247 & 0,042 & 0,247 & 0,166 & 0,066 & 0,030 & 0,122 & 0,418 \\
\hline $\mathrm{Fe}^{3+}$ & 0,208 & 0,682 & 0,475 & 0,559 & 1,383 & 0,561 & 0,786 & 0,538 & 0,591 & 1,678 \\
\hline $\mathrm{Mn}$ & 0,006 & 0,016 & 0,012 & 0,007 & 0,009 & 0,010 & 0,020 & 0,018 & 0,009 & 0,008 \\
\hline \multirow[t]{2}{*}{$\mathrm{Mg}$} & 5,353 & 5,082 & 5,266 & 5,315 & 4,361 & 5,217 & 5,128 & 5,414 & 5,278 & 3,896 \\
\hline & 6,000 & 6,000 & 6,000 & 5,923 & 6,000 & 5,954 & 6,000 & 6,000 & 6,000 & 6,000 \\
\hline $\mathrm{Mg}$ & 0,001 & 0,032 & 0,373 & - & 0,093 & - & 0,048 & 0,121 & 0,103 & 0,009 \\
\hline $\mathrm{Ba}$ & 0,015 & 0,014 & 0,022 & 0,005 & 0,031 & 0,008 & 0,017 & 0,006 & 0,013 & 0,018 \\
\hline $\mathrm{Ca}$ & 0,079 & 0,090 & 0,112 & 0,135 & 0,055 & 0,105 & 0,017 & 0,046 & 0,052 & 0,130 \\
\hline $\mathrm{Na}$ & 0,014 & - & - & 0,013 & - & - & - & - & 0,012 & 0,005 \\
\hline \multirow[t]{2}{*}{$\mathrm{K}$} & 0,984 & 0,889 & 0,488 & 0,853 & 0,887 & 0,878 & 0,897 & 0,890 & 0,828 & 0,841 \\
\hline & 1,093 & 1,025 & 0,995 & 1,006 & 1,066 & 0,991 & 0,979 & 1,063 & 1,008 & 1,003 \\
\hline $\mathrm{F}$ & 0,353 & 0,248 & 0,301 & 0,881 & 0,411 & 1,109 & 0,823 & 0,861 & 0,698 & 0,854 \\
\hline $\mathrm{Cl}$ & - & 0,007 & 0,009 & - & 0,010 & 0,028 & - & - & - & 0,115 \\
\hline
\end{tabular}


Tabela 3. Análises químicas representativas de vermiculita do perfil intempérico de Catalão I.

\begin{tabular}{|c|c|c|c|c|c|c|c|c|c|c|}
\hline Níve I & \multicolumn{5}{|c|}{ Rocha Alterada } & \multicolumn{2}{|c|}{ Micáce o Base } & \multicolumn{3}{|c|}{ Micáceo Médio } \\
\hline Mineral & \multicolumn{5}{|c|}{ Vermiculita } & \multicolumn{2}{|c|}{ Vermiculita } & \multicolumn{3}{|c|}{ Vermiculita } \\
\hline $\mathrm{SiO}_{2}$ & 43,19 & 39,33 & 41,03 & 40,73 & 34,66 & 29,98 & 35,52 & 36,09 & 35,14 & 37,51 \\
\hline $\mathrm{TiO}_{2}$ & 0,96 & 0,27 & 0,37 & 0,14 & 0,62 & 2,11 & 3,48 & 1,95 & 0,86 & 0,77 \\
\hline $\mathrm{Al}_{2} \mathrm{O}_{3}$ & 9,03 & 4,06 & 8,73 & 7,71 & 0,10 & 11,01 & 12,43 & 9,64 & 10,69 & 10,73 \\
\hline $\mathrm{Fe}_{2} \mathrm{O}_{3}$ & 7,49 & 12,83 & 7,29 & 7,34 & 18,88 & 13,95 & 8,65 & 6,67 & 5,60 & 7,79 \\
\hline $\mathrm{MnO}$ & 0,06 & 0,18 & 0,08 & 0,01 & 0,02 & 0,04 & 0,08 & 0,08 & 0,06 & 0,08 \\
\hline $\mathrm{MgO}$ & 28,92 & 28,13 & 30,14 & 29,80 & 25,50 & 20,15 & 25,35 & 24,80 & 25,95 & 25,48 \\
\hline $\mathrm{BaO}$ & n.d. & n.d. & n.d. & n.d. & n.d. & n.d. & n.d. & n.d. & 0,20 & 0,17 \\
\hline $\mathrm{CaO}$ & 0,33 & 0,62 & 0,36 & 0,40 & 0,64 & 0,43 & 0,50 & 0,25 & 0,22 & 0,18 \\
\hline $\mathrm{Na}_{2} \mathrm{O}$ & n.d. & n.d. & n.d. & 0,03 & n.d. & n.d. & n.d. & n.d. & n.d. & n.d. \\
\hline $\mathrm{K}_{2} \mathrm{O}$ & 0,38 & 0,03 & n.d. & 0,20 & 0,07 & 0,04 & 0,09 & 0,71 & 0,25 & 0,27 \\
\hline $\mathrm{F}$ & 0,81 & 0,24 & 0,35 & 0,43 & 0,42 & 0,08 & 0,45 & 0,45 & 0,43 & 0,73 \\
\hline $\mathrm{Cl}$ & 0,01 & 0,01 & n.d. & 0,01 & 0,15 & 0,12 & 0,02 & 0,05 & n.d. & 0,02 \\
\hline Total & 95,02 & 89,49 & 92,37 & 90,70 & 84,50 & 81,47 & 90,47 & 84,32 & 82,89 & 87,25 \\
\hline O_F_Cl & 0,34 & 0,10 & 0,15 & 0,18 & 0,21 & 0,06 & 0,19 & 0,20 & 0,18 & 0,31 \\
\hline CTotal & 94,68 & 89,39 & 92,22 & 90,52 & 84,29 & 81,41 & 90,28 & 84,12 & 82,71 & 86,94 \\
\hline \multicolumn{11}{|c|}{ Fórmula estrutural calculada na base anidra de 22 oxigênios } \\
\hline $\mathrm{Si}$ & 6,091 & 6,030 & 5,950 & 6,029 & 5,840 & 5,114 & 5,334 & 5,775 & 5,685 & 5,795 \\
\hline $\mathrm{Al}$ & 1,500 & 0,733 & 1,490 & 1,344 & 0,020 & 2,211 & 2,198 & 1,816 & 2,036 & 1,951 \\
\hline \multirow[t]{2}{*}{$\mathrm{Fe}^{3+}$} & 0,409 & 1,237 & 0,560 & 0,627 & 2,140 & 0,675 & 0,468 & 0,409 & 0,279 & 0,254 \\
\hline & 8,000 & 8,000 & 8,000 & 8,000 & 8,000 & 8,000 & 8,000 & 8,000 & 8,000 & 8,000 \\
\hline $\mathrm{Ti}$ & 0,101 & 0,032 & 0,040 & 0,016 & 0,078 & 0,271 & 0,393 & 0,235 & 0,104 & 0,089 \\
\hline $\mathrm{Fe}^{3+}$ & 0,385 & 0,242 & 0,235 & 0,189 & 0,252 & 1,114 & 0,509 & 0,394 & 0,401 & 0,651 \\
\hline $\mathrm{Mn}$ & 0,007 & 0,024 & 0,010 & 0,002 & 0,003 & 0,006 & 0,010 & 0,010 & 0,008 & 0,011 \\
\hline \multirow[t]{2}{*}{$\mathrm{Mg}$} & 5,507 & 5,702 & 5,715 & 5,793 & 5,667 & 4,609 & 5,088 & 5,361 & 5,487 & 5,249 \\
\hline & 6,000 & 6,000 & 6,000 & 6,000 & 6,000 & 6,000 & 6,000 & 6,000 & 6,000 & 6,000 \\
\hline $\mathrm{Mg}$ & 0,574 & 0,727 & 0,802 & 0,783 & 0,739 & 0,517 & 0,587 & 0,554 & 0,770 & 0,618 \\
\hline $\mathrm{Ba}$ & - & - & - & - & - & - & - & - & 0,013 & 0,011 \\
\hline $\mathrm{Ca}$ & 0,050 & 0,101 & 0,056 & 0,064 & 0,115 & 0,079 & 0,080 & 0,043 & 0,038 & 0,029 \\
\hline $\mathrm{Na}$ & - & - & - & 0,009 & - & - & - & - & - & - \\
\hline \multirow[t]{2}{*}{$\mathrm{K}$} & 0,067 & 0,005 & - & 0,038 & 0,016 & 0,009 & 0,017 & 0,144 & 0,051 & 0,054 \\
\hline & 0,691 & 0,833 & 0,858 & 0,894 & 0,870 & 0,605 & 0,684 & 0,741 & 0,872 & 0,712 \\
\hline $\mathrm{F}$ & 0,723 & 0,233 & 0,317 & 0,403 & 0,452 & 0,081 & 0,425 & 0,457 & 0,438 & 0,708 \\
\hline $\mathrm{Cl}$ & 0,003 & 0,004 & - & 0,003 & 0,088 & 0,072 & 0,010 & 0,029 & - & 0,008 \\
\hline
\end{tabular}




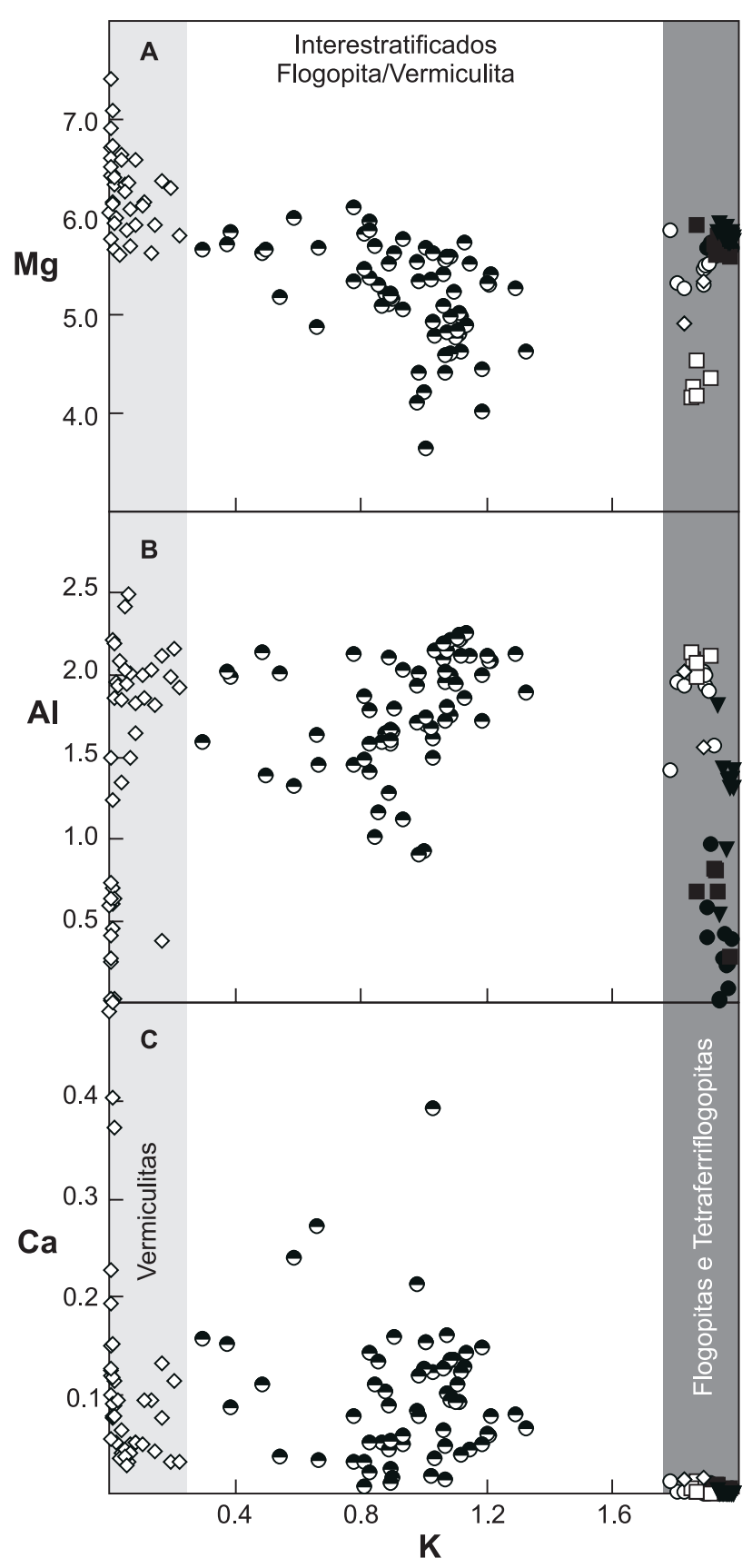

Figura 8. Variações de K vs. A. Mg, B. Al, C. Ca (a.f.u.) para os filossilicatos do complexo Catalão I. Símbolos das flogopitas conforme Figura 6.

por $\mathrm{Fe}$, com $\mathrm{Al}$ e $\mathrm{Mg}$ subordinados, conforme observado por análises de EDS, porém nunca em concentrações compatíveis com a estrutura de filossilicatos.

Desta forma, pode-se entender um pouco melhor o comportamento dos elementos químicos nesta transição

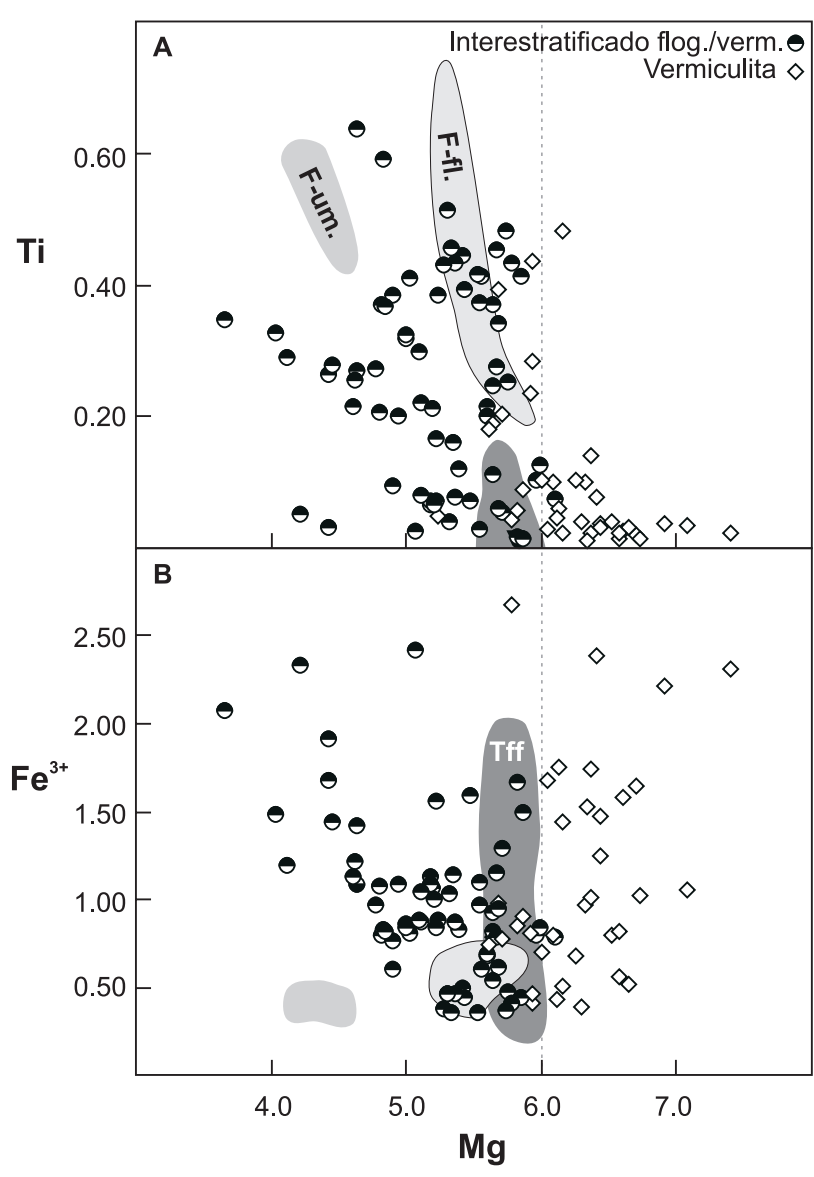

Figura 9. Variações de $\mathrm{Mg}$ vs. A. Ti, B. $\mathrm{Fe}^{3+}$ (a.f.u.) para os produtos da alteração vermiculítica do perfil intempérico do complexo Catalão I. São apresentados os campos das diferentes paragêneses de flogopitas das amostras de rocha sã para fins de comparação.

entre Saprólito Isoalterítico e Saprólito Aloterítico. A partir de Micáceo Topo, a lixiviação dos elementos torna-se cada vez mais intensa, restando na estrutura ou apenas o $\mathrm{Fe}$ (já na forma de hidróxido) ou apenas o $\mathrm{Si}$, e eliminando progressivamente os demais elementos. A partir disso a estrutura do mineral não consegue mais se manter, levando à sua desagregação. No final do Nível Oxidado, este evento que atua na microestrutura passa ocorrer na macro e megaestrutura, gerando o nível aloterítico, não preservando as estruturas ou o arranjo original das rochas do complexo. Assim, a alteração das vermiculitas e interestratificados contribuiu de maneira significativa para a geração do nível aloterítico, uma vez que, de uma forma geral, estes filossilicatos possuem elevada (senão predominante) concentração no perfil. 


\section{Imagens de elétrons retroespalhados}

Imagens de elétrons retroespalhados (backscaterred electron images) de cristais de flogopita, vermiculita e interestratificados, permitem entender um pouco mais sobre as alterações dos minerais micáceos (Figura 10).

Nas imagens das flogopitas e tetraferriflogopitas, podese notar novamente que as características ópticas estão intimamente ligadas com as químicas: da mesma forma que nas análises petrográficas microscópicas, os contatos flogopita-tetraferriflogopita são bruscos, com bordas mais ricas em Fe e núcleos mais aluminosos (Figuras 9a e 9b).

Por meio da correlação das imagens com as análises químicas por microssonda, é possível uma melhor identificação de cristais interestratificados e um melhor entendimento do processo de vermiculitização (Figuras 10c e 10d). Nota-se nas bordas dos cristais interestratificados a coloração mais escura e no núcleo mais claro. Tal variação representa principalmente as diferenças nas concentrações de K, com bordas escuras indicando quase total ausência deste elemento e porções claras ainda apresentando concentrações significativas. Também lamelas de cor cinza escura a preta ocorrem no interior do cristal, indicando uma alteração também relacionada com os planos de clivagem. Opticamente, a cor de tais lamelas é amarela clara, enquanto o cristal como um todo apresenta tonalidade amarronzada. Assim, nota-se que a eliminação de K se dá tanto das bordas para o centro quanto pelos planos de clivagem.

Também, observa-se que os cristais da matriz foram inteiramente transformados para vermiculita, sem praticamente nenhum K (Figuras 9c e 9d). Tal feição confirma que a formação dos interestraficados é uma fase transicional da completa transformação de micas (flogopitas neste caso) para vermiculitas.
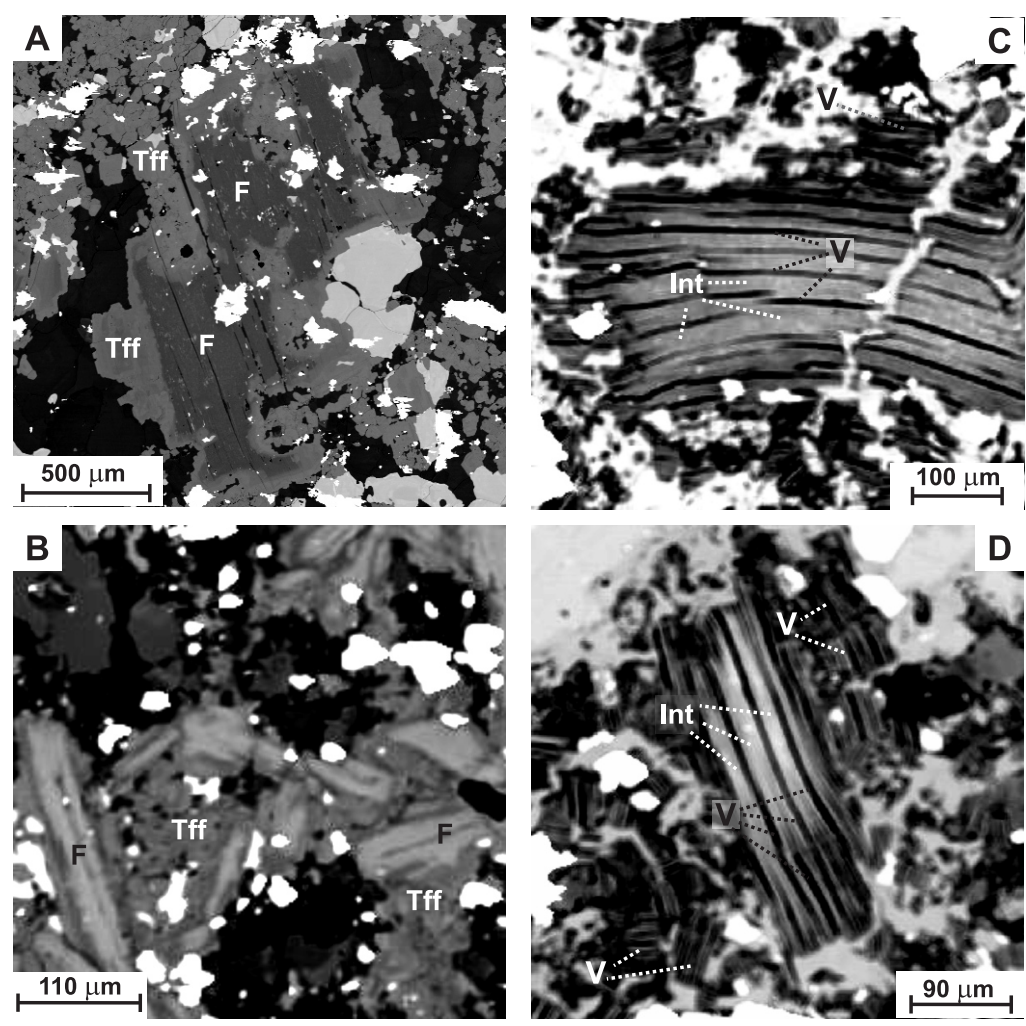

Figura 10. Imagens de elétrons retroespalhados (BSE) dos filossilicatos Complexo Catalão I. Cristais de flogopita e tetraferriflogopita em flogopitito (A) e em rocha ultramáfica metassomatizada (B). C e D. Cristais de interestratificado flogopita/vermiculita, com lamelas de vermiculita, além de cristais vermiculita do nível Rocha. Abreviações: $\mathbf{F}=$ flogopita, Tff = tetraferriflogopita, $\mathbf{V}=$ vermiculita, Int = interestratificado flogopita/vermiculita. 


\section{DISCUSSÃO}

\section{Evolução dos filossilicatos no perfil intempérico do Complexo Catalão I}

A formação de vermiculitas, tanto trioctaédricas como dioctaédricas, está mais frequentemente ligada à alteração de minerais micáceos, nesse caso de estudo a flogopita e tetraferriflogopita. Esse tipo de alteração pode ser subdividido em fatores distintos, quais sejam, 1) liberação de $\mathrm{K}^{+}$; 2) oxidação de $\mathrm{Fe}^{2+}$; e 3) orientação de $\mathrm{OH}^{-}$(Douglas, 1989; Wilson, 2004).

$\mathrm{O}$ modo de liberação do $\mathrm{K}^{+}$das posições interfoliares e sua substituição por outros íons pode ser considerado um processo difusivo (Douglas, 1989). O potássio pode se difundir a partir de todos os espaços interfoliares, com micas evoluindo diretamente para vermiculitas. Em outros casos, $\mathrm{K}^{+}$pode se difundir ao longo de um plano (001) específico, mas não a partir de planos adjacentes a (001). Esta última situação gera, nas micas, zonas em forma de cunha totalmente sem potássio. Este processo resulta nos amplamente conhecidos minerais interestratificados mica-vermiculita.

Estes interestratificados, portanto, representariam produtos de transformação intermediários. Tanto interestratificados regulares quanto irregulares, di- ou trioctaédricos, podem ocorrer em uma ampla variedade de tipos de solos. Entretanto, por representarem produtos intermediários de transformação, não se espera encontrá-los de forma ampla em solos antigos e amplamente alterados.

Processos de alteração tanto de natureza hidrotermal quanto supergênica podem ser atribuídos a tais ocorrências (Brindley, Zalba, Bethke, 1983; Götzinger, 1987; Tsirambides e Michaelidis, 1999). No caso de uma formação hidrotermal desses interestratificados, a temperatura de transformação de flogopita para vermiculita não deve exceder $200-300^{\circ} \mathrm{C}$, limite superior de estabilidade de vermiculitas sob condições de hidrotermalismo (Komarneni e Roy, 1981; Justo et al., 1987). De outra forma, segundo Wilson (1999), um dos principais interestratificados de meios intemperizados é a hidrobiotita. Este mineral consiste em cristais bem formados (não apenas na fração argila) de camadas alternadas de mica e vermiculita, não expansivo, em grande parte dos casos derivado do intemperismo da biotita, aparecendo de forma relativamente rápida. Ainda segundo esse autor, a continuidade do intemperismo de micas vermiculitizadas resultaria numa mais baixa carga negativa na cadeia silicática, conduzindo à formação de produtos esmectíticos tanto de natureza di- quanto trioctaédricas e, em última instância, a um mineral interestratificado com características difratométricas de rectorita.
Diante dos dados obtidos tanto por difratometria de raios $\mathrm{X}$ quanto por análises de dispersão de comprimento de onda (microssonda eletrônica), entende-se que o processo de vermiculitização das flogopitas do Complexo Catalão I gera diferentes produtos (vermiculita e interestratificado flogopita-vermiculita - de formação e características similares à hidrobiotita), relacionados principalmente com a perda de potássio e, como consequência desse processo, há formação de produtos esmectíticos (interestratificados regular de expansividade e características semelhantes à rectorita e mesmo a argilominerais do grupo da esmectita) pontualmente localizados em porções superiores do perfil (a partir de Micáceo Topo). Dessa forma, a evolução do perfil como um todo permite a interpretação do processo de vermiculitização estando eminentemente associado à alteração intempérica.

A Figura 11 apresenta os principais caminhos para a formação de argilominerais em solos (Wilson, 1999), juntamente com a sequência de evolução intempérica obtida para as flogopitas do Complexo Catalão I. A caolinita, identificada em análises de raios $\mathrm{X}$ nos níveis superiores do perfil, provavelmente está associada a uma contribui-

FLOGOPITA TETRAFERRIFLOGOPITA

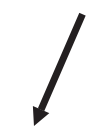

INTERESTRATIFICADO FLOGOPITA/VERMICULITA

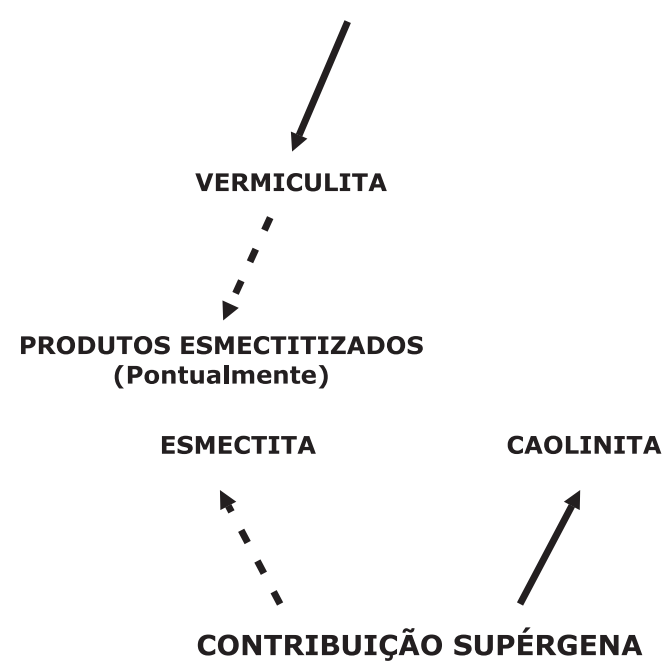

Figura 11. Evolução dos filossilicatos no perfil intempérico do Complexo Catalão l, com base nos caminhos para a formação de argilominerais em solos (Wilson, 1999). 
ção supérgena, conforme já propôs Imbernon (1993). O mesmo também pode ocorrer para a esmectita.

\section{Implicações gerais}

Elementos químicos como $\mathrm{Al}, \mathrm{Fe}$ e $\mathrm{Mg}$ são elementos de controle na especificação dos concentrados de fosfatos. Segundo Assis (1996), os concentrados das principais jazidas brasileiras geralmente apresentam teores desses contaminantes em níveis mais elevados que os concentrados provenientes dos fosfatos sedimentares de grandes produtores mundiais, como Marrocos e Estados Unidos. Em realidade, a indústria de fertilizantes, consumidora dos concentrados apatíticos, é muito rigorosa nos teores desses elementos, em virtude de sua ação prejudicial à qualidade dos fertilizantes produzidos.

Tais contaminantes são encontrados nos minerais silicáticos presentes nas jazidas fosfáticas, principalmente os filossilicatos. Em razão dos tipos de filossilicatos presentes em um determinado depósito, podem ocorrer vários problemas, tais como contaminação dos concentrados por $\mathrm{Al}, \mathrm{Fe}$ e $\mathrm{Mg}$ ou geração de lamas nas condições usuais de atrição da célula mecânica de flotação, podendo tornar o processo menos seletivo. Especialmente no Complexo Catalão I, onde rochas flogopitíticas e seus produtos de alteração são abundantes, o entendimento inicial da formação e distribuição dos minerais no perfil intempérico é de suma importância para subsidiar posteriores estratégias para um melhor tratamento do minério. Conforme Guimarães e Lenharo (2002), as variações composicionais, o desequilíbrio das cargas e a distribuição heterogênea nas diversas frentes de lavra, evidenciam a complexidade composicional do minério de Catalão I da mina da Ultrafértil.

Além disso, a caracterização dos filossilicatos bem como de sua evolução no perfil intempérico contribui para os estudos de potencialidade da recuperação da vermiculita como um recurso mineral explorável na mina, uma vez que nos últimos anos a produção nacional teve um crescimento na ordem de 35\% (Ugarte, Sampaio, França, 2009). Nesse sentido, cabe enfatizar que das 5 riquezas minerais principais no complexo - apatita, pirocloro, monazita, anatásio e vermiculita - apenas as duas primeiras estão em processo de lavra (Ribeiro, 1998; Toledo et al., 2004b), sendo o fosfato minerado pela Ultrafértil e pela Copebrás, e o nióbio, pela Mineração Catalão.

A relevância dessa linha de pesquisa pode ser medida segundo a importância do mercado fosfático no país, as elevadas concentrações destes minerais em alguns corpos mineralizados, na procura constante por melhorias no aproveitamento do minério, e no crescimento do mercado de vermiculita como bem de consumo.

\section{CONCLUSÕES}

Os minerais micáceos encontrados no horizonte rocha sã do Complexo Catalão I são classificados como flogopitas, de paragêneses diferentes, e tetraferriflogopitas, resultado de diferentes produtos de metassomatismo carbonatítico. Nos horizontes Rocha Alterada e Saprólito Isoalterítico, os filossilicatos derivados de micas são vermiculita e interestratificado regular flogopita-vermiculita, caracterizando um processo principal de vermiculitização no perfil laterítico.

Vermiculitas e interestratificado flogopita-vermiculita apresentam basicamente as mesmas variações químicas desde o horizonte Rocha Alterada até próximo ao topo de Saprólito Isoalterítico, onde encontram-se preservados apenas pseudomorfos (compostos principalmente por hidróxidos de Fe) destes minerais. Subordinadamente, em porções superiores e pontuais deste horizonte, a alteração das flogopitas vermiculitizadas gera produtos esmectíticos, caracterizados principalmente pela ocorrência de interestratificado regular expansível com características semelhantes à rectorita e mesmo pela ocorrência de esmectita. No topo do horizonte isoalterítico e no horizonte aloterítico há ocorrência de caolinita, provavelmente estando esta associada a contribuições supérgenas ao perfil. O mesmo pode ocorrer para a esmectita.

A sequência evolutiva dos filossilicatos neste complexo apresenta a seguinte ordem de formação: flogopita, interestratificado flogopita-vermiculita, vermiculita, produtos esmectitizados (pontualmente), esmectita e caolinita, sendo os dois últimos provavelmente associados à contribuição supérgena. Tal sequência é compatível com a das proposições mais recentes para a formação de argilominerais em solos.

As principais diferenças entre as flogopitas e seus produtos da alteração vermiculítica dizem respeito aos teores de $\mathrm{K}^{+}$que diminuem significativamente, à oxidação do $\mathrm{Fe}^{2+}$, e ao aumento do $\mathrm{Mg}$ no sítio octaédrico e sua incorporação ao sítio interfoliar, mudanças estas próprias do processo de vermiculitização. Além disso, a presença de interestratificados (produtos intermediários de alteração) é indicativa principalmente de perfis pouco alterados e relativamente recentes.

\section{AGRADECIMENTOS}

Agradecemos ao geólogo Dr. Carlos Cordeiro Ribeiro pelo acompanhamento nos trabalhos de campo e pelas informações sobre a geologia do complexo, bem como à Ultrafértil S.A. pela autorização de acesso á área e amostragem dos materiais. Igualmente somos gratos ao Prof. Francisco Rubens Alves pelas sugestões e apoio durante o desenvolvi- 
mento do projeto. Esse artigo é resultado de um trabalho de formatura desenvolvido durante o ano de 2002 no IGc/USP, ao qual também prestamos o devido reconhecimento. Também de relevante importância foram os comentários e sugestões oferecidos pelos relatores desta revista.

\section{REFERÊNCIAS}

ALMEIDA, F. F. M. Relações tectônicas das rochas alcalinas mesozóicas da região meridional da plataforma sul-americana. Revista Brasileira de Geociências, v. 13, p. 139-158, 1983.

AMARAL, G.; BUSHEE, J.; CORDANI, U. G.; KAWASHITA, K.; REYNOLDS, J. H. Potassium-argon ages of alkaline rocks from southern Brazil. Geochimica et Cosmochima Acta, v. 31, p. 117-142, 1967.

ARAÚJO, A. L. N.; CARLSON, R. W.; GASPAR, J. C.; BIZZI, L. A. Petrology of kamafugites and kimberlites from the Alto Paranaíba Alkaline Province, Minas Gerais. Brasil. Contributions to Mineralogy and Petrology, v. 142, p. 163-177, 2001.

ARAÚJO, D. P. Metassomatismo no complexo carbonatítico Catalão I: implicações para a composição do magma carbonatítico e para o metassomatismo carbonatítico do manto superior. 1996. 415 f. Dissertação (Mestrado) - Universidade de Brasília, Brasília, 1996.

ARAÚJO, D. P.; GASPAR, J. C. Química mineral dos carbonatitos e rochas associadas de Catalão I, GO. In: CONGRESSO BRASILEIRO DE GEOLOGIA, 37., 1992, São Paulo. Anais... São Paulo: SBG, 1992. p. 90-91.

ASSIS, S. M. Aspectos Fundamentais da Flotação do Minério Fosfático de Tapira, MG. 1996. 211 f. Tese (Doutorado) - Escola de Engenharia, Universidade Federal de Minas Gerais, Minas Gerais, 1996.

BAECKER, M. L. A mineração de Nióbio do solo residual laterítico e a petrografia das rochas ultramáficas-alcalinas do Domo de Catalão I, Goiás. 1983. 113 f. .Dissertação (Mestrado) - Instituto de Geociências, Universidade de Brasília, Brasília, 1983.

BASSET, W. A. The geology of vermiculite occurrences. Clays and Clay Minerals, v. 10, p. 61-96, 1963.

BRINDLEY, G. W.; ZALBA, P. E.; BETHKE, C. M. Hydrobiotite, a regular 1:1 interstratification of biotite and vermiculite layers. American Mineralogist, v. 68, p. 420-425, 1983.
BROD, J. A.; GASPAR, J. C.; ARAÚJO, D. P.; GIBSON, S. A.; THOMPSON, R. N.; JUNQUEIRA-BROD, T. C. Phlogopite and tetra-ferriphlogopite from Brazilian carbonatite complexes: petrogenetic constraints and implication for mineral-chemistry systematics. Journal of Asian Earth Sciences, v. 19, p. 265-296, 2001.

CARVALHO, W. T. Aspectos geológicos e petrográficos do complexo ultramáfico-alcalino de Catalão I, GO. In: CONGRESSO BRASILEIRO DE GEOLOGIA, 28., 1974, Porto Alegre. Anais... Porto Alegre: SBG, 1974, v. 5, p. 107-123.

DANNI, J. C. M. BAECKER, M. L. RIBEIRO, C. C. The Geology of the Catalão I carbonatite complex. In: INTERNATIONAL KIMBERLITE CONFERENCE, 5., 1991, Brasilia. Field Guide Book ... Brasilia: CPRM, 1991. p. 25-30.

DEER, W.A.;HOWIE, R. A.;ZUSSMAN, J.An introduction to the Rock-Forming Minerals. 2.nd ed. Inglaterra: Pearson Education Limited, 1992. 696 p.

DOUGLAS, L. A. Vermiculites. In: DIXON, J. B.; WEED, S. B. Minerals in Soils Environments. 2.nd. ed. Madison: SSSA, 1989. p. 635-674. (Soil Science Society of America Book Series).

FOSTER, M. D. Interpretation of the composition of vermiculites and hydrobiotites. Clays and Clay Minerals, v. 10, p. 70-89, 1963.

GIBSON, S. A.; THOMPSON, R. N.; LEONARDOS, O. H.; DICKIN, A. P.; MITCHELL, J. G. The Late Cretaceus Impact of the Trindade mantle plume. Evidence from largevolume mafic, potassic magmatism in SE, Brazil. Journal of Petrology, v. 36, p. 189-230, 1995.

GOMES, C. B.; COMIN-CHIARAMONTI, P. Some notes on the Alto Paranaiba Igneous Province. In: COMINCHIARAMONTI, P.; GOMES, C. B. Mesozoic to Cenozoic alkaline magmatism in the Brazilian Platform. São Paulo: EDUSP-FAPESP, 2005. p. 317-340.

GÖTZINGER, M. A. Mineralogy and Genesis of Vermiculite in Serpentinites of the Bohemian Massif in Austria. Mineralogy and Petrology, v. 36, p. 93-110, 1987.

GUIMARÃES, E. M.; LENHARO, S. L. R. Caracterização mineralógica dos filossilicatos do minério de fosfato micáceo do depósito de Catalão I, Brasil. In: SIMPÓSIO SOBRE O CRETÁCEO DO BRASIL, 6., 2002, São Pedro. Boletim... São Pedro: SBG, v. 1. p. 421-426. 
HIRANO, H.; KAMITANI, M.; SATO, T.; SUDO, S. Niobium Mineralization of Catalão I Carbonatite Complex, Goiás, Brazil. Geological Survey of Japan. Report of International Research and Development Cooperation, 1987. p. 23-55. (ITIT Projects No 8316).

IMBERNON, R. A. L. Evolução geoquímica e mineralógica dos produtos de alteração intempérica sobre as rochas do Complexo Alcalino-Carbonatítico de Catalão I, Goiás. 1993. 131 f. Dissertação (Mestrado) - Instituto de Geociências, Universidade de São Paulo, São Paulo, 1993.

JUSTO, A.; MAQUEDA, C.; PEREZ-RODRIGUEZ, J. L.; LAGALY, G. An unusually expandable low-charge vermiculite. Clays and Clay Minerals , v. 22, p. 319-327, 1987.

KOMARNENI,S.;ROY,R.Hydrothermaltransformations in candite overpack materials and their effects on cesium and strontium sorption. Nuclear Technology, v. 54, p. 118-122, 1981.

LAPIDO-LOUREIRO, F. E. V. 1995. A mega província carbonatítica Brasil-Angola e seus recursos minerais - Geologia, Petrografia, Geoquímica, Geologia Econômica. 1995. 305 f. Tese (Doutorado) - Faculdade de Ciências, Universidade de Lisboa, Portugal, 1995.

LAPIDO-LOUREIRO, F. E. V., MELO MONTE, M. B.; NASCIMENTO, M. Agrominerais - Fosfato In: LUZ, A. B.; LINS, F. F. (Org.). Rochas e Minerais Industriais Usos e Especificações. 2. ed. Rio de Janeiro: CETEM/MCT, 2009, p. 141-181.

MEYER, H. O. A.; GARWOOD, B. L.; SVISERO, D. P.; SMITH, C. B. Alkaline ultrabasic intrusions in western Minas Gerais, Brazil. In: INTERNATIONAL KIMBERLITE CONFERENCE, 5., 1994, Araxá. Proceedings.... Rio de Janeiro: CPRM, v.1, 1994, p. 140-155.

MOORE, D. M.; REYNOLDS, R. C.; J. R. X-ray Diffraction and the Identification and Analysis of Clay Minerals. Oxford: Oxford University Press, 1989. 332 p.

OLIVEIRA, S. M. B.; IMBERNON, R. A. L. Weathering and REE concentration in the Catalão I carbonatitic complex, Central Brazil. Journal of South American Earth. Science, v. 11, p. 379-388, 1998.

PEREIRA, V. P. Alteração no Maciço Alcalino-carbonatítico de Catalão I (GO, Brasil). 1995. 279 f. Tese (Doutorado) - Instituto de Geociências, Universidade Federal do Rio Grande do Sul, Rio Grande do Sul, 1995.
RIBEIRO, C. C. Maciço de Catalão I, GO. Goiás: Ultrafértil, 1998. 15 p. (Relatório interno)

SONOKI, I. K.; GARDA, G. M. Idades K-Ar de rochas alcalinas do Brasil Meridional e Paraguai Oriental: compilação e adaptação às novas constantes de decaimento. Boletim IG-USP, v. 19, p. 63-85, 1988.

TOLEDO, M. C .M. Mineralogia dos principais fosfatos do maciço Alcalino-Carbonatítico de Catalão I (GO) e sua evolução no perfil laterítico. 1999. 193 f. Tese (Livre-Docência) - Instituto de Geociências, Universidade de São Paulo, São Paulo, 1999.

TOLEDO, M. C. M. O grupo da crandallita no manto laterítico sobre o maciço carbonatítico de Catalão I (GO, Brasil). Geochimica Brasiliensis, v. 14, p. 71-95, 2000.

TOLEDO, M. C. M.; LENHARO, S. R.; FERRARI, V. C.; FONTAN, F.; PARSEVAL, P.; LEROY, G. The compositional evolution of apatite in the weathering profile of the Catalão I alkaline-carbonatitic complex, Goiás, Brazil. The Canadian Mineralogist, v. 42, p. 1139-1158, 2004a.

TOLEDO, M. C. M.; OLIVEIRA, S. M. B.; FONTAN, F.; FERRARI, V. C.; PARSEVAL, P. Mineralogia, morfologia e cristaloquímica da monazita de Catalão I (GO, Brasil). Revista Brasileira de Geociências, v. 34, p.135-146, $2004 \mathrm{~b}$.

TSIRAMBIDES, A.; MICHAILIDIS, K. An X-ray, EPMA, and oxygen isotope study of vermiculitized micas in the ultramafic rocks at Askos, Macedonia, Greece. Applied Clay Science, v. 14, p. 121-140, 1999.

UGARTE, J. F. O.; SAMPAIO, J. A.; FRANÇA, S. C. A. Vermiculita. In: LUZ, A. B.; LINS, F. F. (Org.). Rochas e Minerais Industriais - Usos e Especificações. 2. ed. Rio de Janeiro: CETEM/MCT, 2009. p. 865-888.

ULBRICH, H. H. G. J.; GOMES, C. B. Alkaline rocks from Brazil. Earth Science Reviews, v. 17, p. 135-154, 1981.

WILSON, M. J. The Origin and formation of clay minerals in soils: past, present and future perspectives. Clay Minerals, v. 34, p. 7-25, 1999.

WILSON, M. J. The Weathering of the primary rockforming minerals: processes, products and rates. Clay Minerals, v. 39, p. 233-266, 2004. 